Research Article

\title{
Optimization and Mechanical Characteristics of Spatial Arc Antislide Pile
}

\author{
You-Sheng Deng, Cheng-Pu Peng $(\mathbb{D}$, Jun-Cong Liu, Ling-Tao Li, and Yun-Bo Fu
}

Xi'an University of Science and Technology, Xi'an 710054, China

Correspondence should be addressed to Cheng-Pu Peng; 1837513499@qq.com

Received 7 September 2021; Accepted 9 October 2021; Published 18 October 2021

Academic Editor: Zhiguo Zhang

Copyright (c) 2021 You-Sheng Deng et al. This is an open access article distributed under the Creative Commons Attribution License, which permits unrestricted use, distribution, and reproduction in any medium, provided the original work is properly cited.

\begin{abstract}
To improve the stress state of traditional antislide pile and utilize the stable soil on both sides of a landslide and slope foot, a spatial arc antislide pile supporting structure was proposed. Based on numerical calculation, a parametric study was conducted to assess the influence of the rise-span ratio on the stress state of the supporting structure, the displacement of the pile top, and the earth pressure in the front of the pile. The optimal rise-span ratio was 3-16 according to the numerical simulation results. An indoor model test at the optimal rise-span ratio was carried out, recording the pile strain and the earth pressure in front of the pile. The results showed that some indices increased with the increase in rise-span ratio, such as the load transferred to the pile at the arch foot, the bending moment of the piles, the displacement of the pile top, and the earth pressure; within a certain depth near the pile top, the soil in front of the pile is loose during the loading processes, and the earth pressure at the range was zero. The overall safety factors of the four supporting models were $2.42,2.66,2.78$, and 2.84, respectively, which can satisfy the requirements for practical engineering. The test results verify the feasibility and rationality of the spatial arc antislide pile supporting structure, which can provide a new idea for landslide treatment.
\end{abstract}

\section{Introduction}

There are many natural and artificial slopes in mountainous and hilly areas with large fluctuation of elevation. The slope is prone to be failed at the effect of rainfall, earthquake, and load acted on the top of the slope, resulting in extensive damage to people and property. At present, the main methods used in landslide treatment are drainage facilities, reducing load, pressure load acted on the negative direction, antislide structure, and so on. Among the methods, the antislide pile is widely used, which is embedded below the sliding surface and relies on flexural stiffness and earth pressure in front of the pile to resist the sliding force. The main research on antislide pile mainly focuses on the type and layout of antislide structure [1,2], soil arching effect [3], sliding force distribution [4], pile-soil interaction [5], and so on. The type of antislide pile is various. The simplest type is cantilever antislide pile, but the supporting capacity is limited. In large slope, it is urgent to improve the supporting capacity of the antislide structure. Xin et al. [6] analysed the supporting capacity of single-row and multirow piles through model tests and studied the formation process of sliding surface and failure mode of piles; the results showed that multirow piles can increase antislide force effectively. Portal antislide pile has the advantages of large flexural stiffness and antislide force. Qian and Tang [7] proposed a double-row portal frame antislide structure, calculated the internal force and deformation characteristics, and successfully applied it on the landslide treatment in the Three Gorges Reservoir area. Chen et al. [1] put forward a hybrid A-frame micropile and researched the feasibility and seismic performance of the structure through numerical simulation and model test. Wang et al. [8] applied a pair of vertical and two inclined micropiles to compose a composite structure on reinforcing slope during the excavation process, but the flexural stiffness difference between micropile and pile cap was large, and the piles had a large flexural deflection. Rao et al. [9] studied the dynamic characteristics and pile-soil 
interaction of micropile and analysed the influence of pile length, diameter, and spacing on the dynamic performance of the embankment.

Arch is a good bearing structure. The pile-beam-arch method is a common construction method for subway stations, which can well constrain the ground settlement [10]. To take full use of the antislide force of stable soil on the both sides of landslide, some scholars have researched an arc antislide pile, which was arranged on the plane arch line, and the pile top was connected by an arc-shaped coupling beam. $\mathrm{Yu}$ [11] used composite arc antislide pile for slope and proposed a variety of composite arc antislide structures for the first time. The results showed that the composite structure has good spatial mechanical performance and flexural stiffness, the displacement on the pile top is significantly reduced, and the terrain conditions can be fully utilized. Wang [12] examined the internal force distribution and deformation regularity of arc antislide piles, systematically elaborated the basic idea of arc antislide piles, and concluded that the arc antislide piles can improve the uneven stress and deformation of pile body and reduce displacement on pile top. Zhang and Deng [13] researched arc antislide piles connected by a coupling beam on the pile top and verified the feasibility of the structure by an indoor model test, numerical simulation, and actual engineering.

The arc antislide supporting structure, arranged on an arc axis and combined by a coupling beam, can improve the stress state of pile body, reduce displacement on the pile top, and fully utilize stable soil on the side of landslide. However, the pile is arranged on the same level, and it is difficult to fit the change of the slope altitude and adjust the rise-span ratio. The spatial arc antislide piles are arranged on the inclined plane of the slope, and the projection of the piles on the plane is an arc. The pile top is connected by a coupling beam along the inclined surface to form an integral antislide structure. The load can be transferred to the pile on both sides along the coupling beam. The depth of landslide at the slope foot is small, and the antislide pile at arch foot fully utilizes flexural stiffness and soil resistance in front of the pile to resist sliding force, so the large volume anchor is not necessary, acted as the arch foot. In numerical simulation, the supporting effect of the structure at different rise-span ratios was analysed, such as the pile bending moment, displacement on the pile top, earth pressure in front of the pile, and overall safety factor of slope. Finally, the mechanical performance of the supporting structure was studied in the indoor model test compared with the results of numerical simulation. Both results verify the rationality and feasibility of the spatial arc antislide pile and provide a new idea for landslide treatment.

\section{Numerical Simulation}

2.1. Parameters. In an arch structure, the rise-span ratio is an important parameter that affects the internal force of the structure. According to an actual slope, the numerical model based on ABAQUS software was established, as shown in Figure 1. In the model, the rise-span ratio was set at 1-16, 2$16,3-16$, and 4-16, respectively. The parameter of the efficient pile length was out of consideration and the bottom of all piles was arranged on a same horizontal plane, so the pile length can be determined. The pile length at each model is shown in Table 1 . The cross section of the antislide piles and the coupling beam was rectangular, with the dimensions of $40 \mathrm{~cm} \times 30 \mathrm{~cm}$ and $60 \mathrm{~cm} \times 60 \mathrm{~cm}$, respectively, as described in Figures 2 and 3. Figure 4 is the layout of antislide pile and coupling beam on the horizontal plane. In the model, the soil was a single material, and the constitutive model was an ideal elastic-plastic model following the Mohr-Coulomb criterion. The piles and coupling beam were made of C30 concrete, and the elastic model was used. The specific parameters of materials are shown in Table 2. The pile-soil interaction can be divided into two parts: normal contact and tangential contact. The normal is hard contact, and the tangential is the Coulomb friction model, and the friction coefficient is set as the tangent value of internal friction angle of soil. The natural sliding surface, underwater, temperature, and other factors were out of consideration.

2.2. Load Scheme. After the establishment of the model, the stress and displacement under the gravity were calculated. The ground stress was balanced by introducing prestress calculated in the previous step. After the balance step, vertical uniform distributed pressure was applied on the top of the slope to simulate static vehicle load. The load was divided into five levels, each of which is $30 \mathrm{kPa}$. By applying vertical load on the slope surface, pushing force of the soil acted on the antislide piles.

\subsection{Results and Analysis}

2.3.1. Bending Moment of Antislide Pile. Because of the effect of arc coupling beam, the spatial arc antislide pile has bending moment along the slope and across the slope. As the distribution of the supporting structure and external load was symmetrical, P1, 3, 5, and 6 were only analysed.

(1) Bending Moment across the Slope. $\left(M_{x}\right)$. In the composite supporting structure, the load transferred from the pile on the arch crown to the pile on the arch foot along the coupling beam, so $M_{x}$ was existed. The diagram of $M_{x}$ under the level 5 load is shown in Figure 5. The maximum of $M_{x}$ was at the top of pile, and $M_{x}$ at the bottom section of the pile was close to zero. In the aspect of stress state, the antislide pile was similar to a vertical beam, which is fixed at one end and hinged at the other end. The point of inflexion appeared in the middle and upper part of the pile. In the four models with different rise-span ratios, the variation regularity of $M_{x}$ was the same. In the model with the rise-span ratio of 1-16, $M_{x}$ was smaller, so the load transferred to the pile at the arch foot was also limited. However, $M_{x}$ of the other three models was basically the same. Because P6 was located on the symmetry axis of the structure, the antisymmetric internal force $M_{x}$ was close to zero.

In the model with the rise-span ratio of $3-16, M_{x}$ of the antislide piles is shown in Figure 6. Because of the effect of coupling beam, $M_{x}$ decreased with the increase in pile number, $M_{x}$ of P1 was the maximum, and $M_{x}$ of P6 was the 


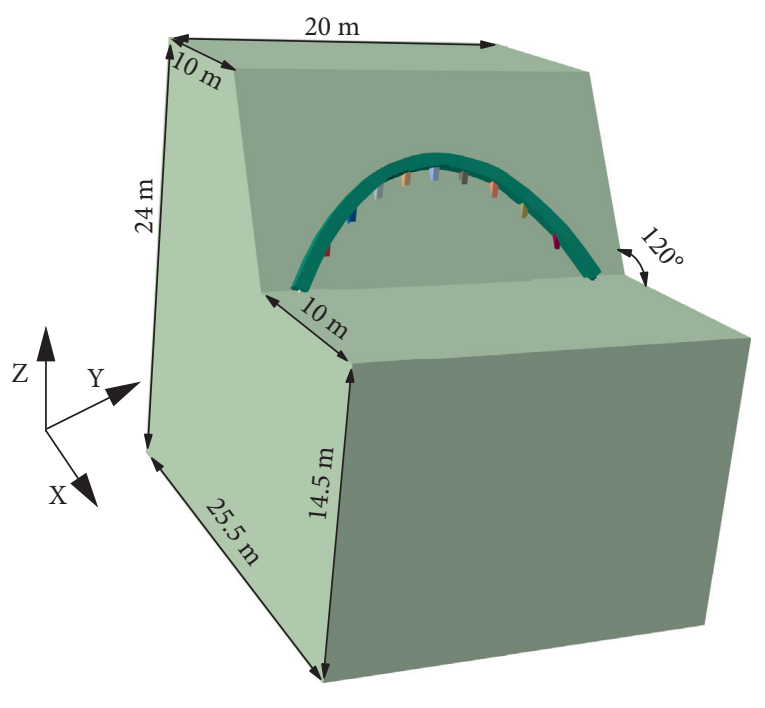

(a)

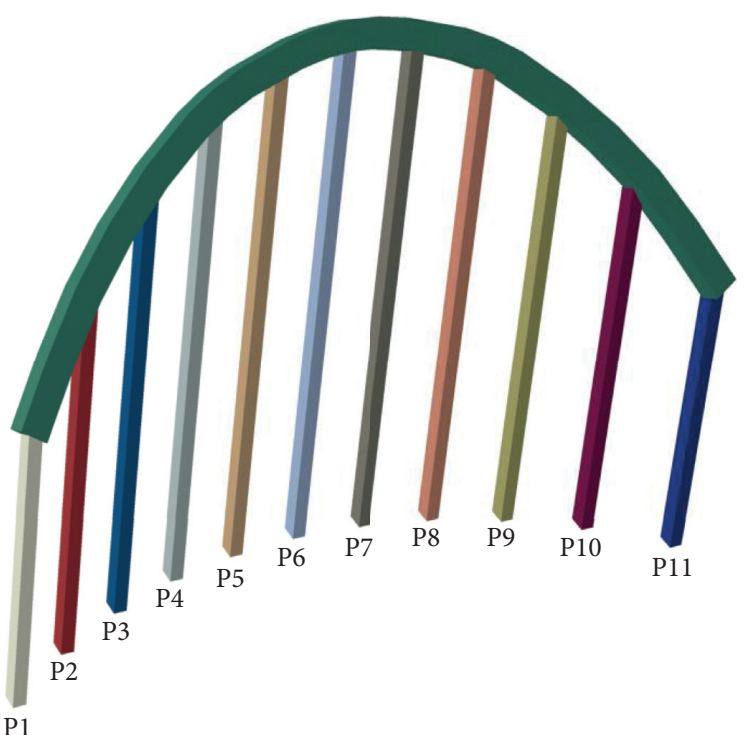

(b)

FIgURE 1: Diagram of numerical simulation: (a) slope model and (b) antislide piles + coupling beam.

TABLe 1: Pile length (unit: $\mathrm{m}$ ).

\begin{tabular}{lccccc}
\hline Rise-span ratio & P1(11) & P2(10) & P3(9) & P4(8) & P5(7) \\
\hline $1-16$ & 6.3 & 6.9 & 7.4 & 7.8 & 7.9 \\
$2-16$ & 6.3 & 7.6 & 8.7 & 9.2 & 9.6 \\
$3-16$ & 6.3 & 8.4 & 9.8 & 10.8 & 11.3 \\
$4-16$ & 6.3 & 9.2 & 11.1 & 12.3 & 13 \\
\hline
\end{tabular}

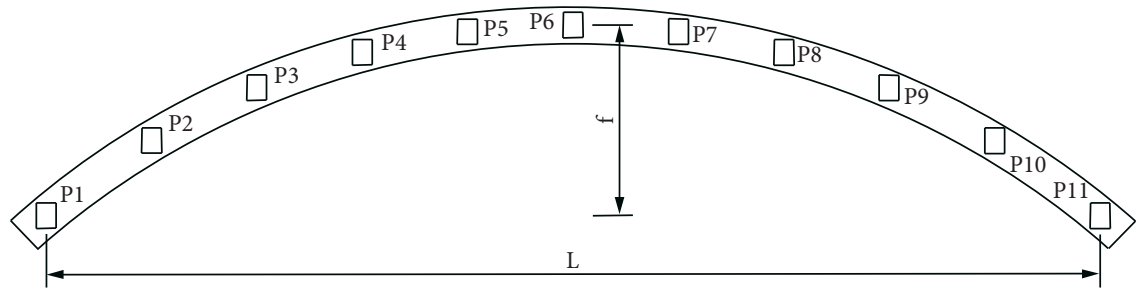

$\mathrm{f}$ :rise of arch

L:length of arch

Figure 2: Layout of piles and coupling beam.

smallest. The variation verified the load transferred from the arch crown to the arch foot. In the load transfer process, the coupling beam acted as a bridge. According to the value of $M_{x}$, the axial force of the coupling beam was negative that can fully utilize the compressive performance of concrete and avoid bending-shearing failure.

(2) Bending Moment along the Slope. $\left(M_{y}\right)$. Under the $5^{\text {th }}$ level of load, the bending moment $M_{y}$ of antislide piles is shown in Figure 7. With the increase in rise-span ratio, $M_{y}$ of some sections changed from positive to negative and increased continuously. The effect of coupling beam transferring load was more evident, which reflected the load transfer law of arc antislide structure. In the supporting model with large rise-span ratio, the piles located on the middle position were arranged closer to the top of the slope, the pile length was larger, and the location of stable soil was deeper. In Figure 7, with the increase in rise-span ratio, the number of points of inflexion decreased, $M_{y}$ of each pile section increased in negative direction. $M_{y}^{y}$ was almost negative at the rise-span ratio of 3-16 and 4-16. The maximum of $M_{y}$ was not located on the pile top because of the constraints of coupling beam.

Figure 8 is the diagram of $M_{y}$ with the rise-span ratio of 3-16. The maximum of P1 appeared on the pile top, and there were two peak points below the pile top. Except for the positive bending moment under the fifth level load, the other bending moments were negative. The bending moment 


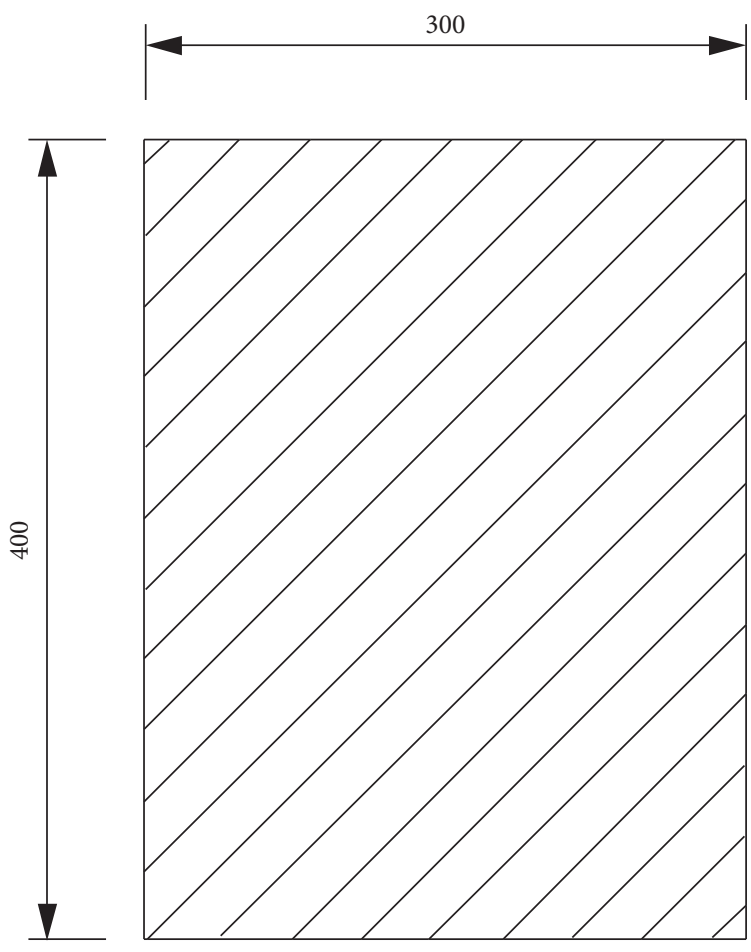

Figure 3: Cross section of pile (mm).

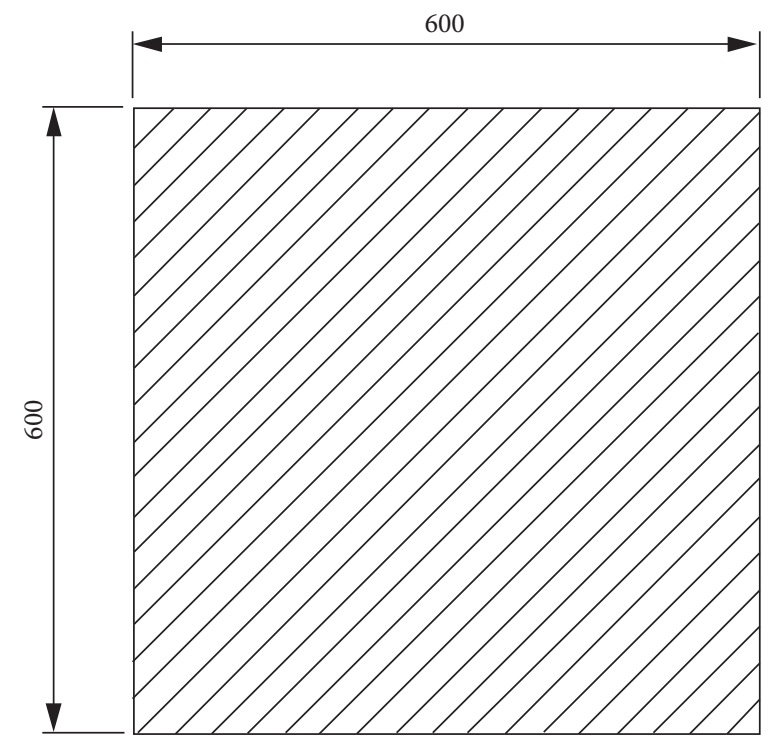

Figure 4: Cross section of coupling beam (mm).

TABle 2: Material parameters.

\begin{tabular}{lccccc}
\hline Name & Unit weight $\left(\mathrm{kN} / \mathrm{m}^{3}\right)$ & Cohesion $(\mathrm{kPa})$ & Internal friction angle $\left(^{\circ}\right)$ & Poisson's ratio & Elastic modulus $(\mathrm{MPa})$ \\
\hline Loess & 20.8 & 42.5 & 30.05 & 0.32 & 16.38 \\
Coupling beam & 24 & - & - & 0.2 & $3 \times 10^{4}$ \\
Antislide pile & 24 & - & - & 0.2 & $3 \times 10^{4}$ \\
\hline
\end{tabular}



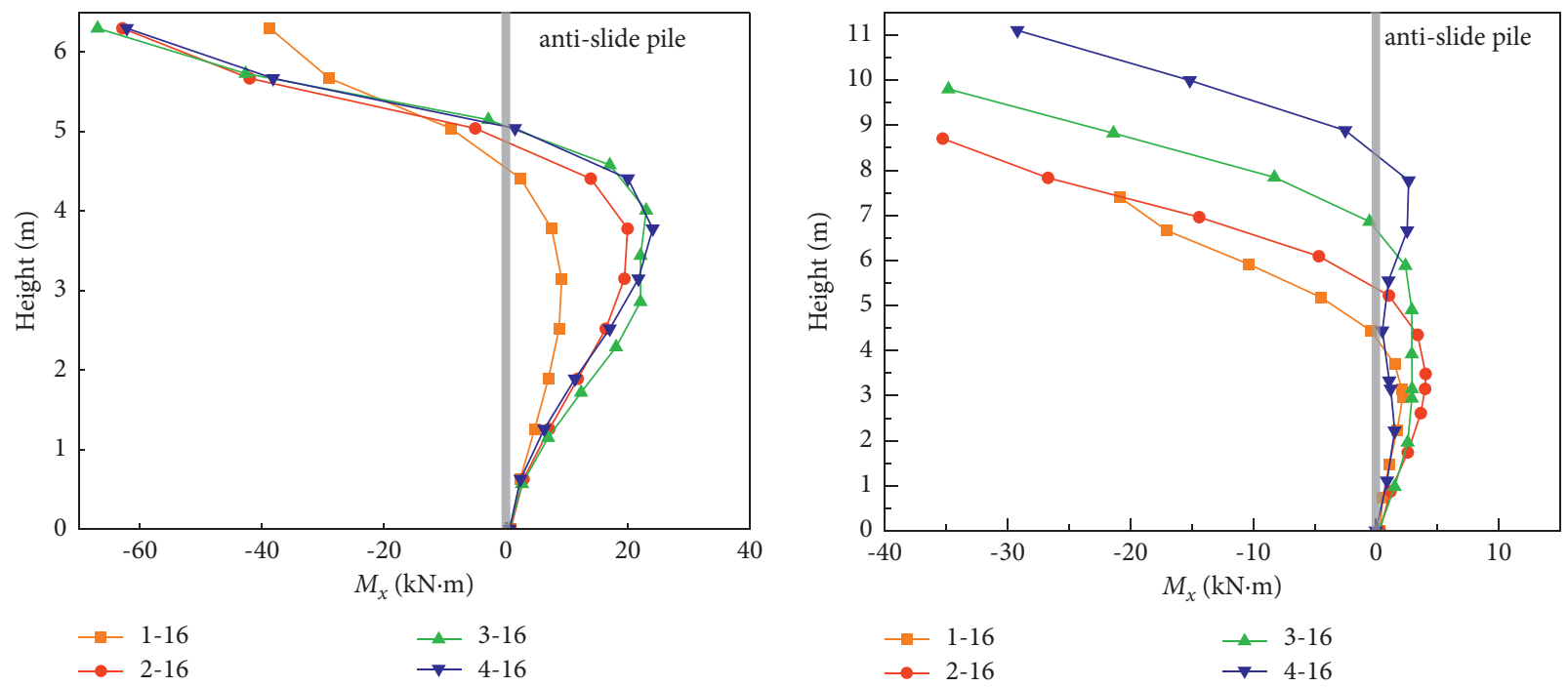

(a)

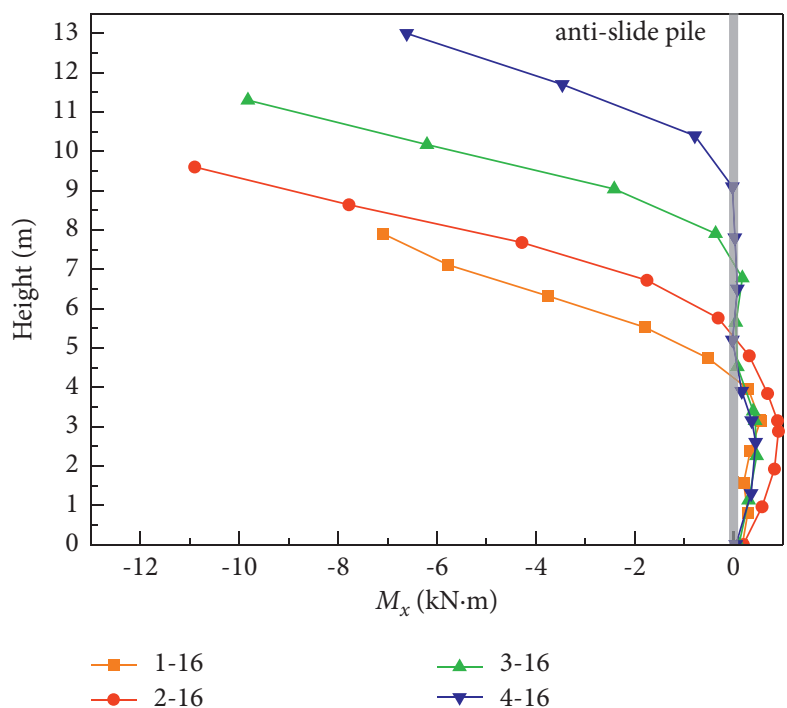

(c)

(b)

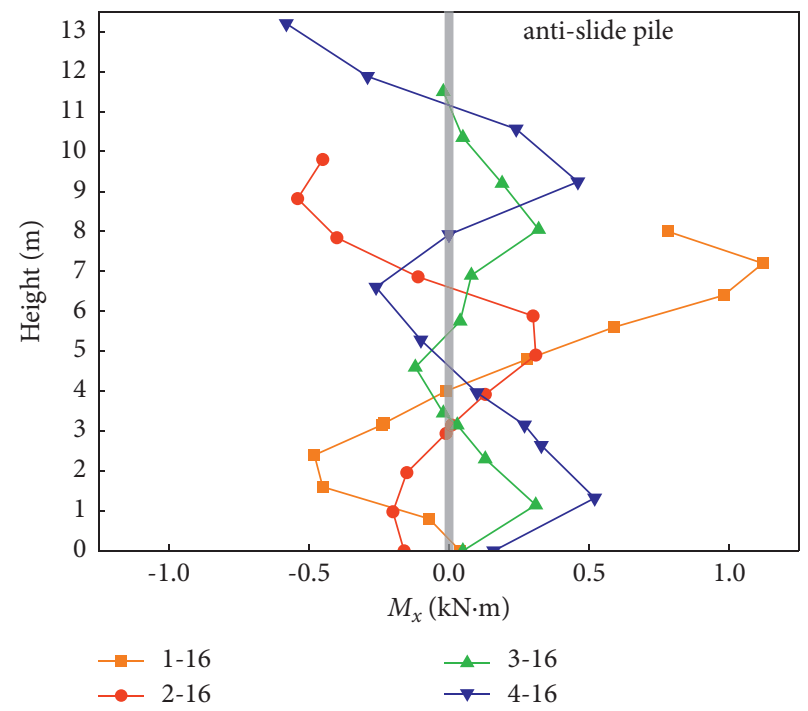

(d)

Figure 5: $M_{x}$ : (a) P1; (b) P3; (c) P5; (d) P6.

diagram of other piles was harp-shaped, and the maximum bending moment was not at the pile top, but at the height of $7 \sim 9 \mathrm{~m}$, which fully reflected the restraint effect of the coupling beam. The peak point distribution of each pile was similar.

\subsubsection{Displacement on the Pile Top}

(1) Displacement across the Slope. The displacement on the pile top across the slope (U2) under the fifth level load is shown in Figure 9. The U2 of P6 was a few, close to zero. The larger the rise-span ratio was, the larger the U2 was. And from arch crown to arch foot, the U2 increased continuously. The load transferred to the pile at the arch foot superimposed continuously and reached the maximum at P1.
(2) Displacement along the Slope. Figure 10 is the diagram of displacement on the pile top along the slope (U1) under the fifth level load. With the increase in rise-span ratio, the load along the slope direction borne by the pile at arch foot increased and the U1 of P1 increased continuously. When the rise-span ratio was 4-16, the largest U1 appeared on the top of the pile at the arch foot because the rise-span ratio was too large, and the load transferred to the pile was also significant. Among the three models with smaller rise-span ratio, the U1 was small, so the stable soil on the both sides of landslide provided great soil resistance.

When the rise-span ratio was 3-16, the displacement of each pile top is shown in Figure 11. The closer to the top of the slope the pile was, the larger the U1 was and the smaller the $\mathrm{U} 2$ was. When the load was $150 \mathrm{kPa}$, the maximum of U1 was at P6, about $21 \mathrm{~mm}$. The U2 of each pile top was small, 


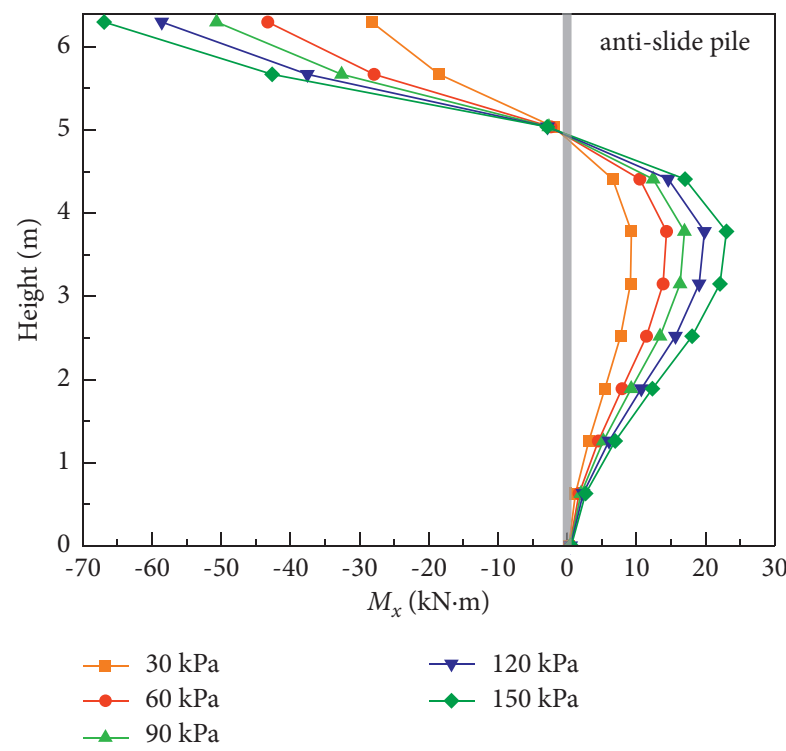

(a)

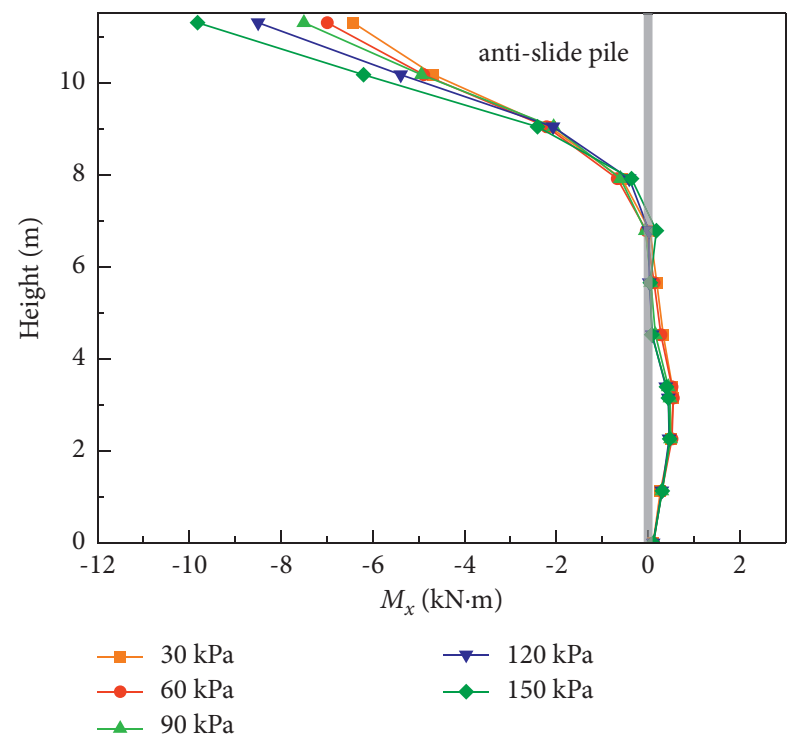

(c)

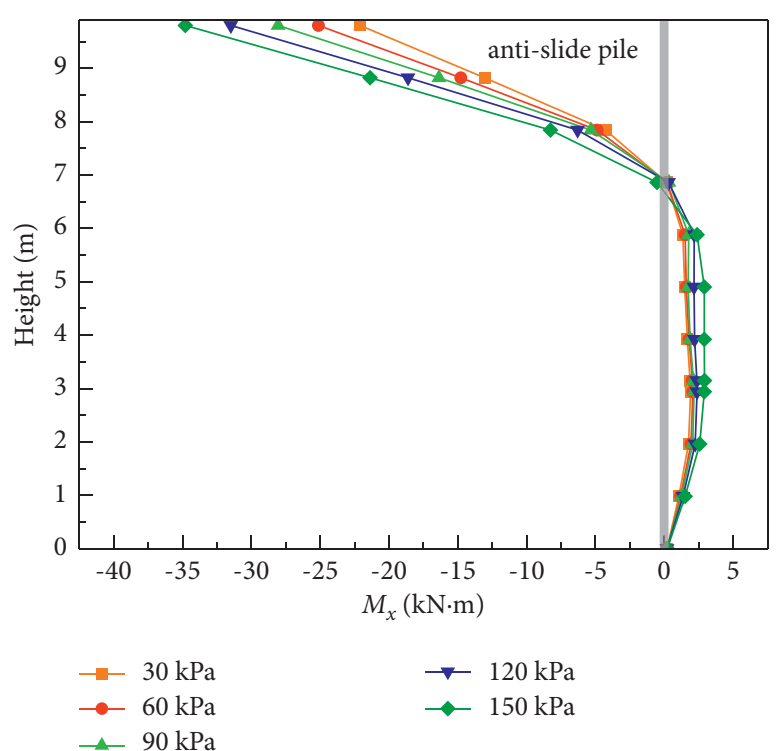

(b)

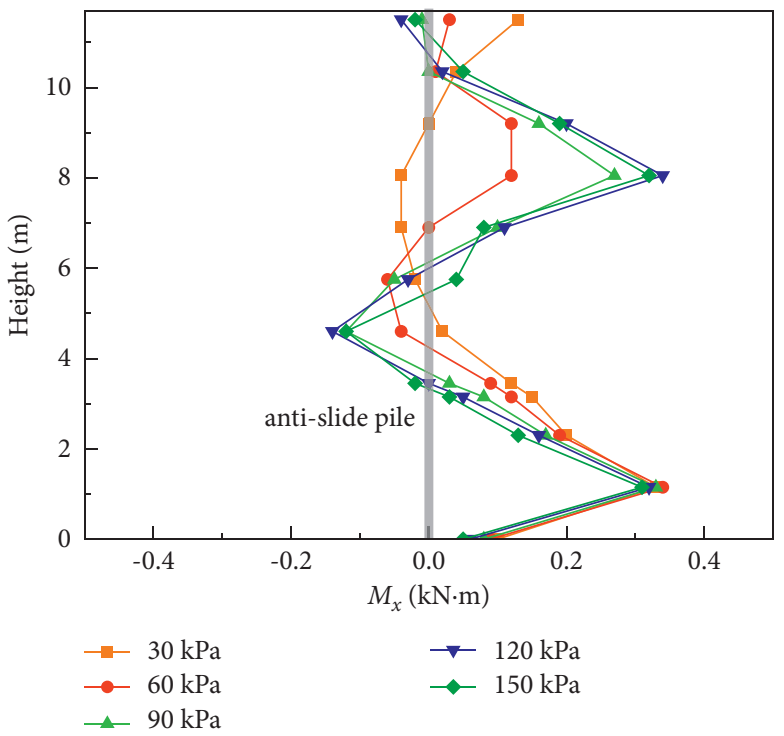

(d)

Figure 6: $M_{x}$ (3-16): (a) P1; (b) P3; (c) P5; (d) P6.

and the maximum was $-4.42 \mathrm{~mm}$, appeared at $\mathrm{P} 1$. The variation regularity was similar to $M_{x}$.

2.3.3. Earth Pressure in front of Pile. Under the fifth level load, the earth pressure in front of the pile diagram is shown in Figure 12. With the increase in rise-span ratio, the earth pressure at the upper part of the P1 increased continuously, but the variation amplitude at the bottom was a few. In the model with relatively small rise-span ratio, the pile located on the middle position was close to the slope foot, the first peak point of earth pressure close to pile top was large, and the soil in front of the pile provided greater resistance. The change of earth pressure was consistent with the variation of $M_{y}$.

Figure 13 is the diagram of earth pressure in front of piles with the rise-span ratio of 3-16. The maximum appeared at the top of P1. The model fully utilized the soil resistance in front of the pile P1 which acted as the arch foot. Except for $\mathrm{P} 1$, in a certain range near the pile top, the soil in front of the piles was loose, the soil and the pile were separated, and the earth pressure was zero. As known in Figure 13(e), the range was about $7 \mathrm{~m}$ away from the pile bottom. During the loading processes, the variation of earth pressure at the first 

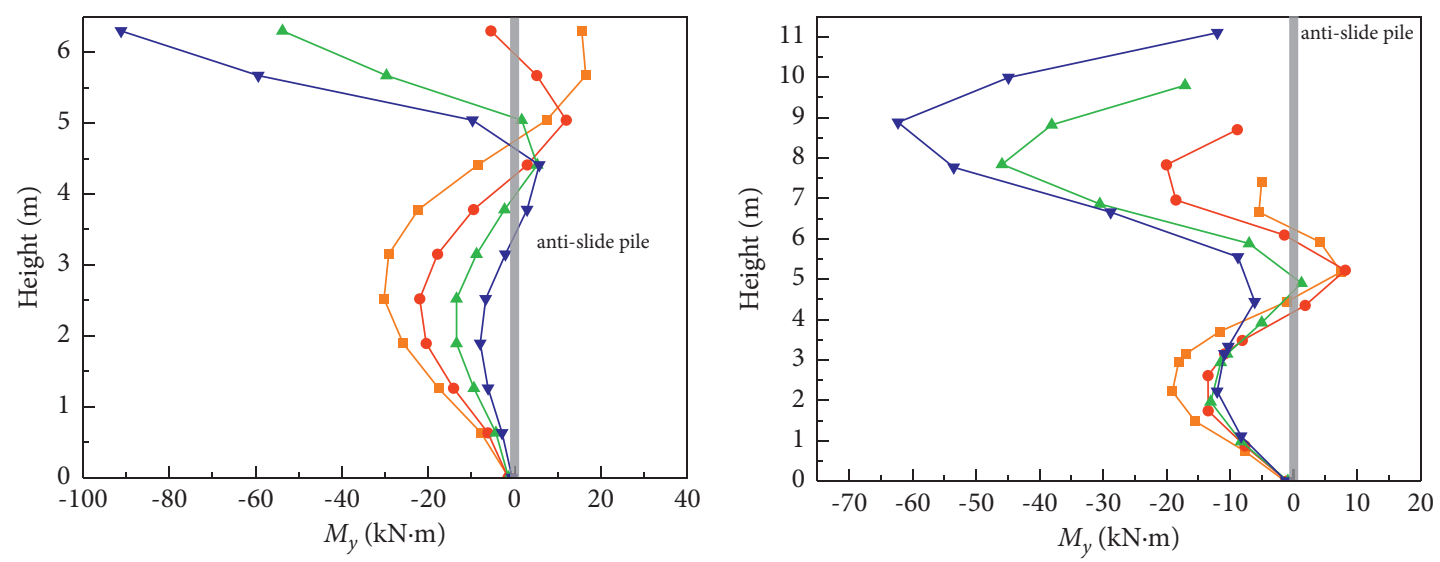

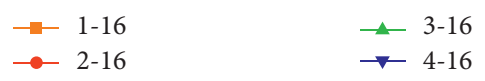

(a)

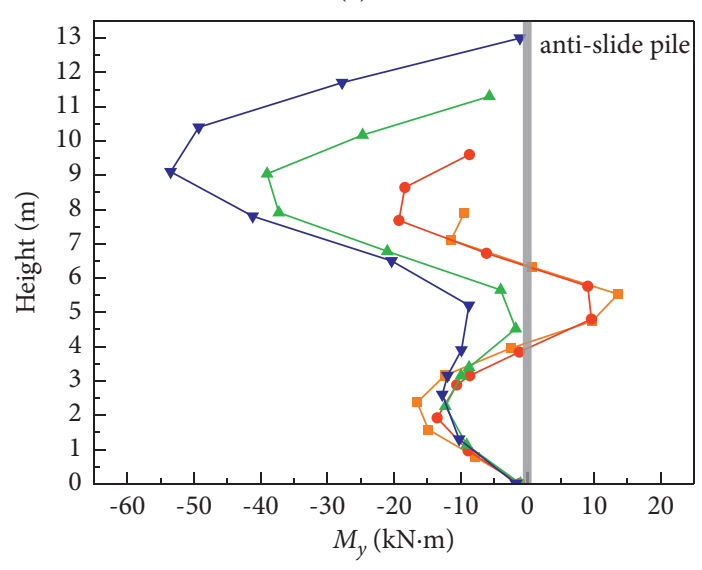

$\rightarrow-1-16$

$-2-16$

$$
\triangle \text { 3-16 }
$$$$
\rightarrow 4-16
$$

(c)

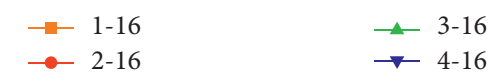

(b)

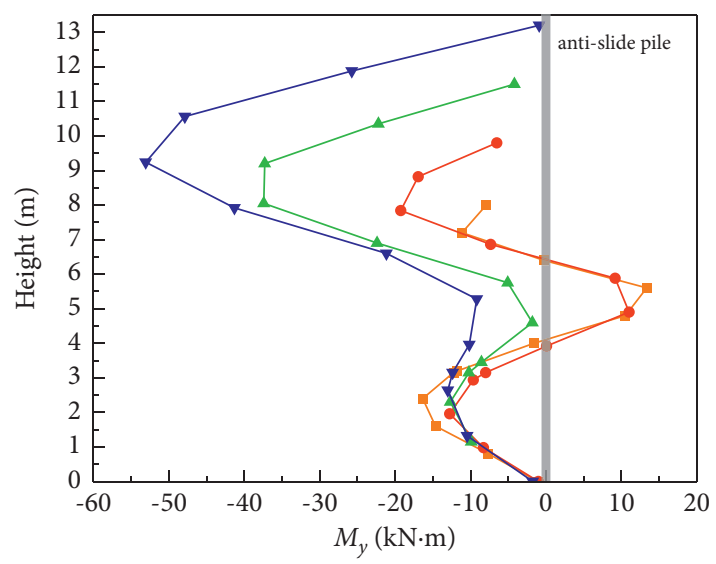

$\rightarrow-1-16$

$\longrightarrow$ 3-16

(d)

Figure 7: $M_{y}$ : (a) P1; (b) P3; (c) P5; (d) P6.

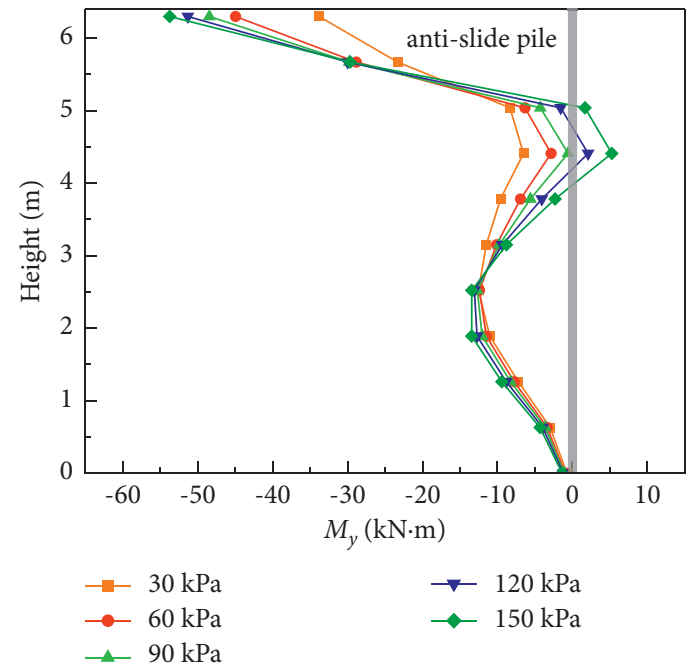

(a)

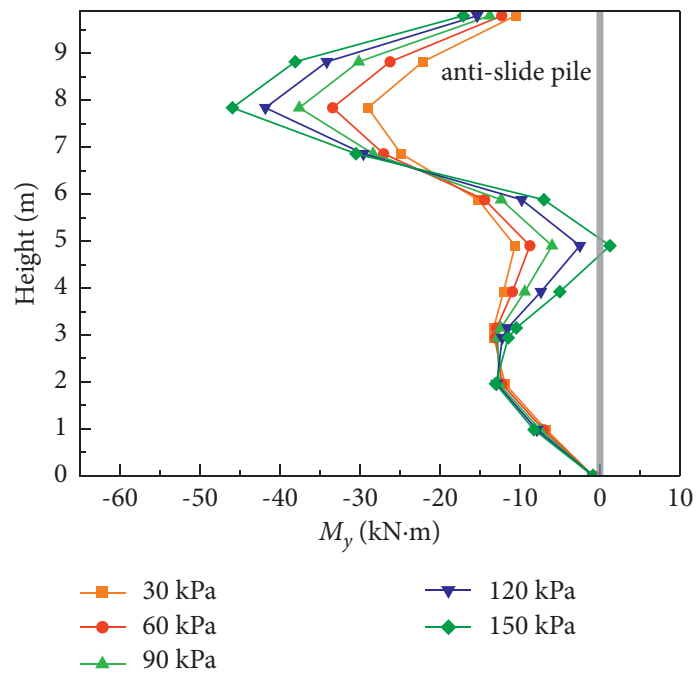

(b)

Figure 8: Continued. 


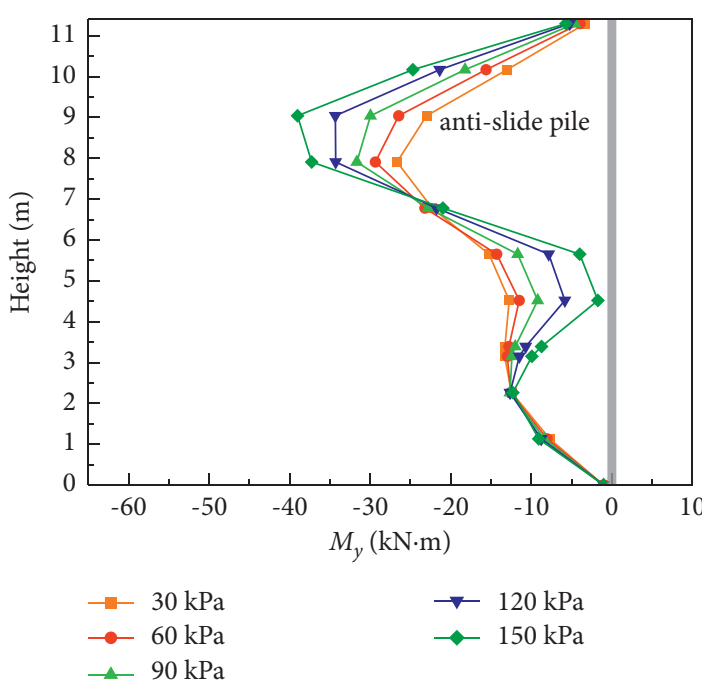

(c)

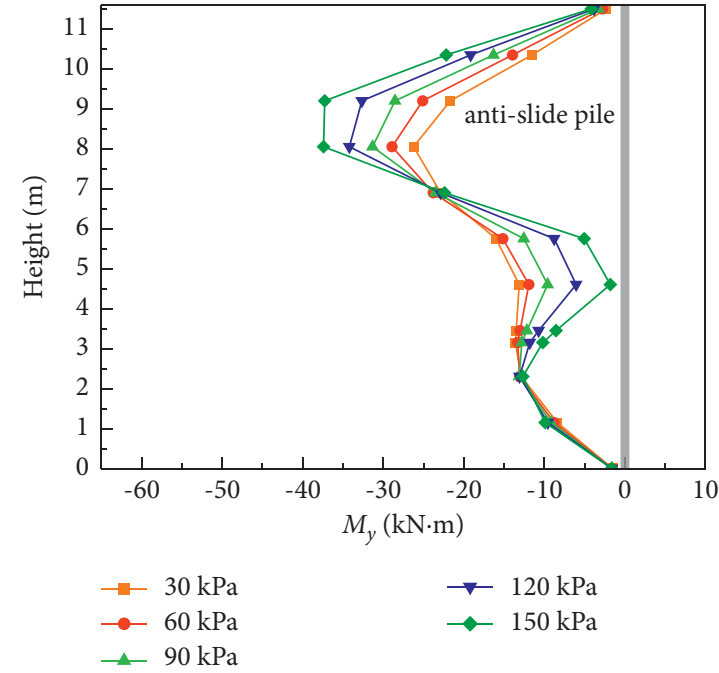

(d)

Figure 8: $M_{y}$ (3-16): (a) P1; (b) P3; (c) P5; (d) P6.
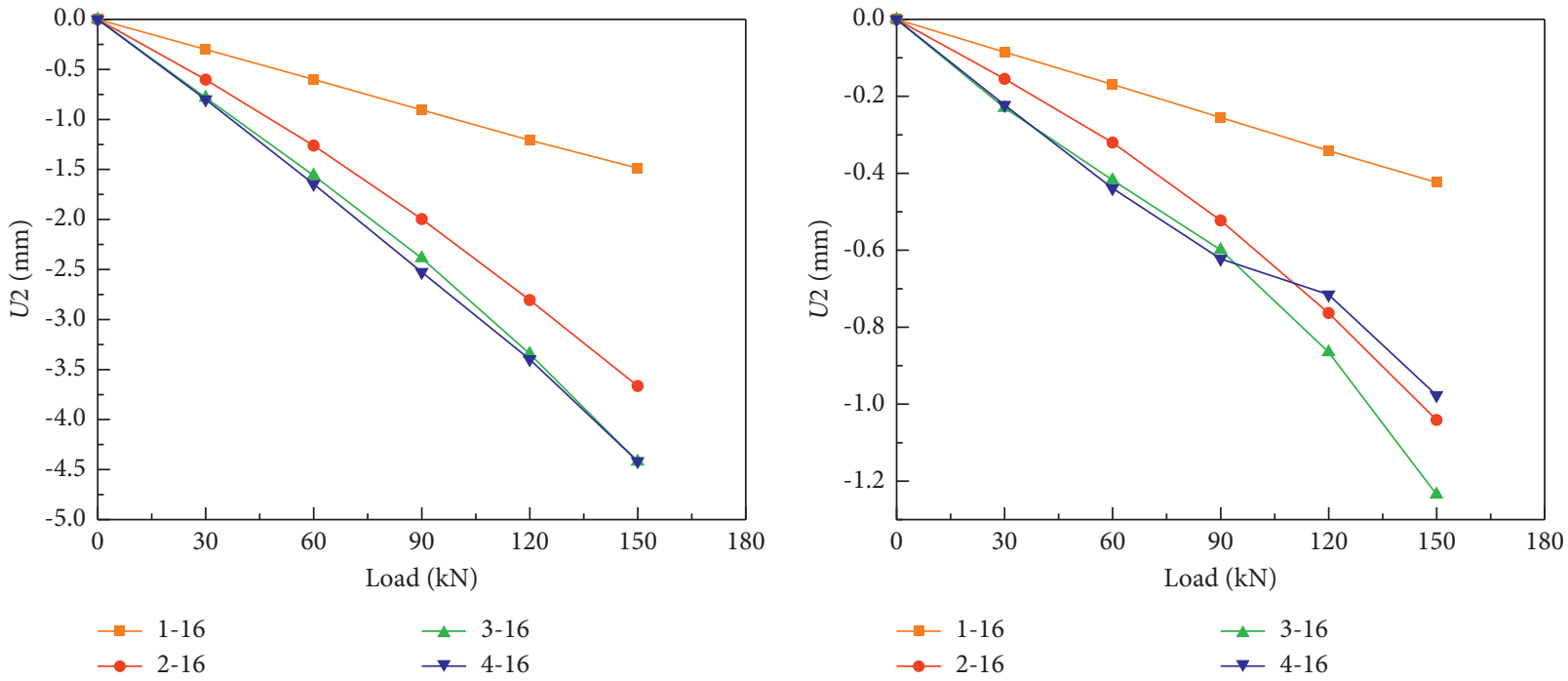

(a)
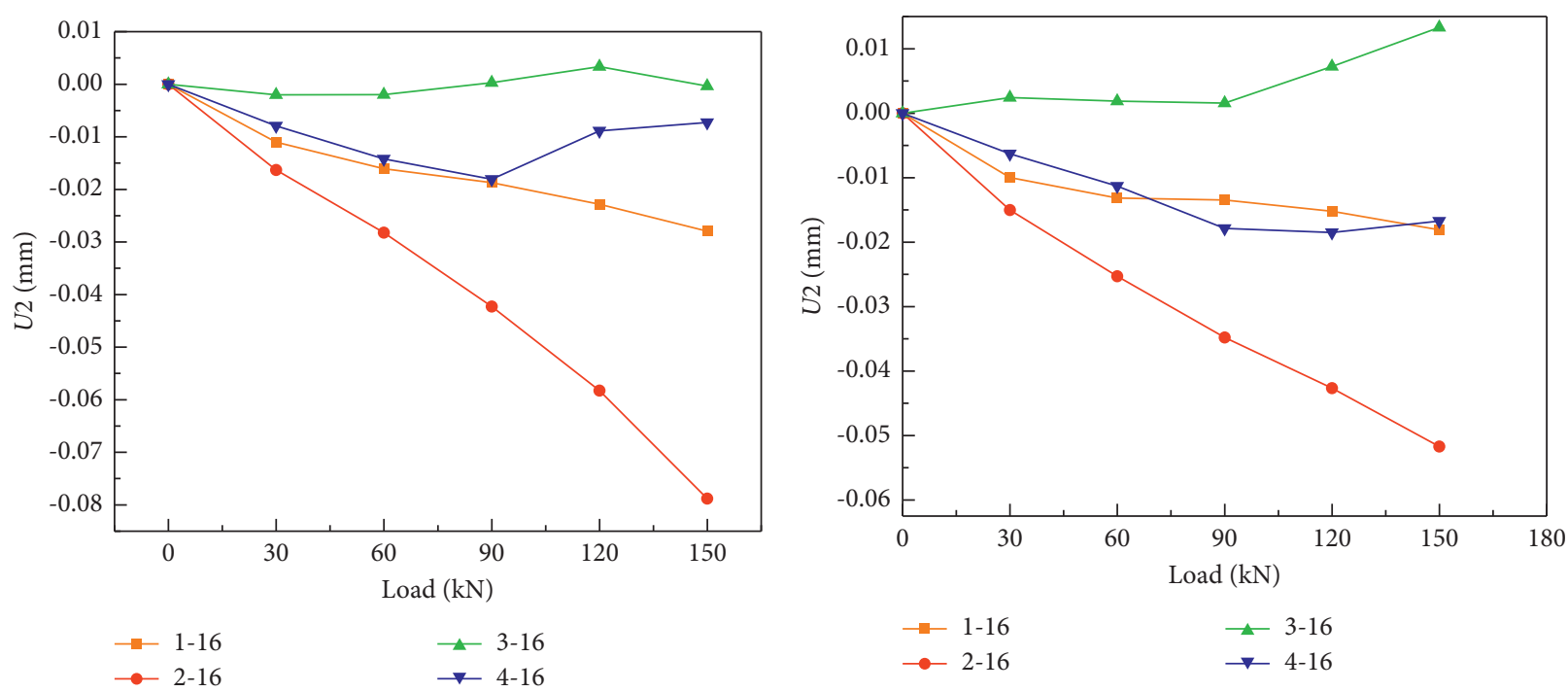

$\rightarrow 1-16$
$\rightarrow-16$

$\rightarrow-3-16$

(c)

(d)

Figure 9: U2: (a) P1; (b) P3; (c) P5; (d) P6. 


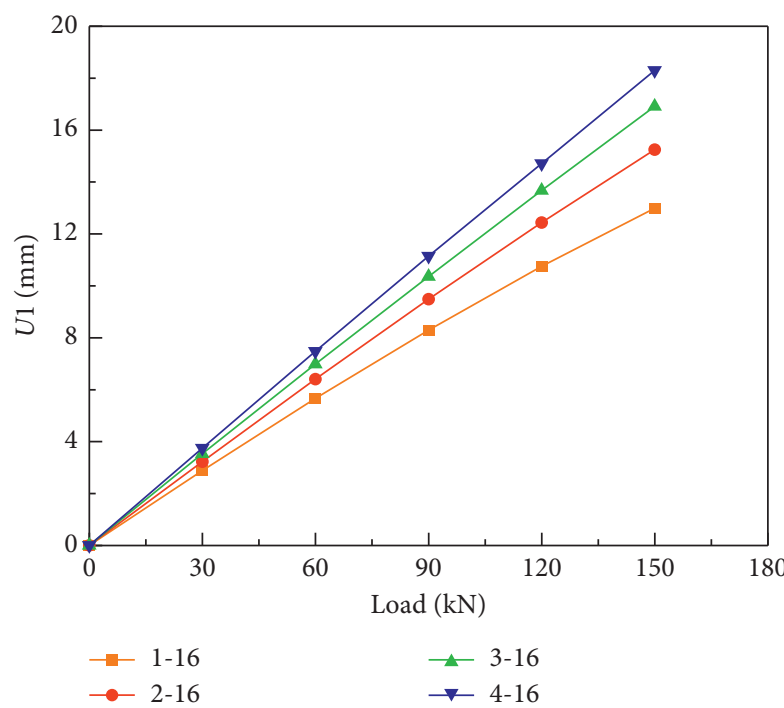

(a)

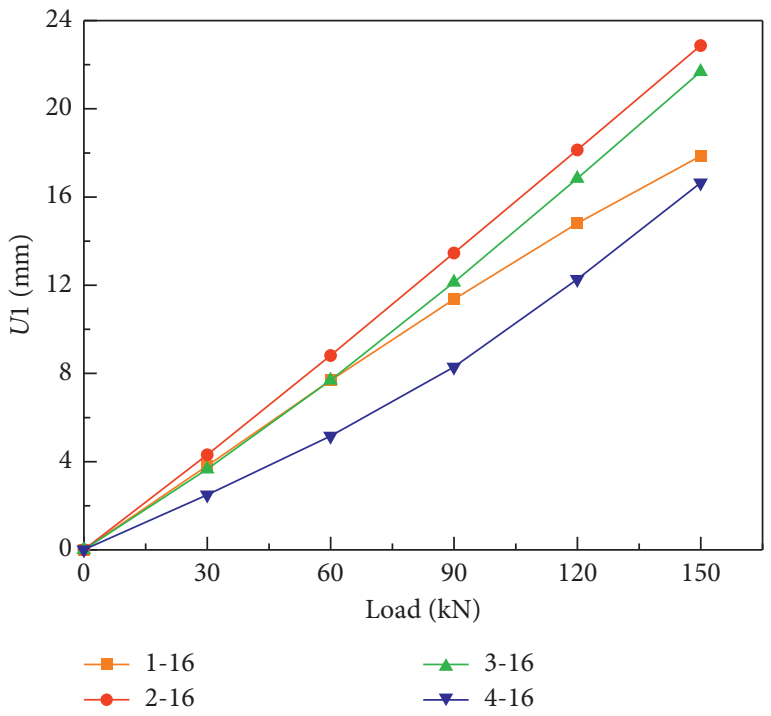

(c)

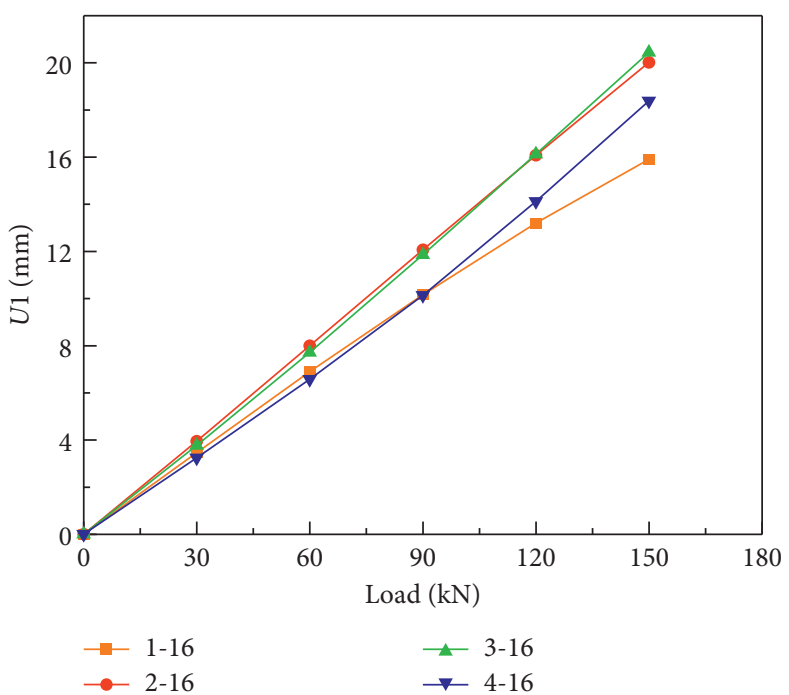

(b)

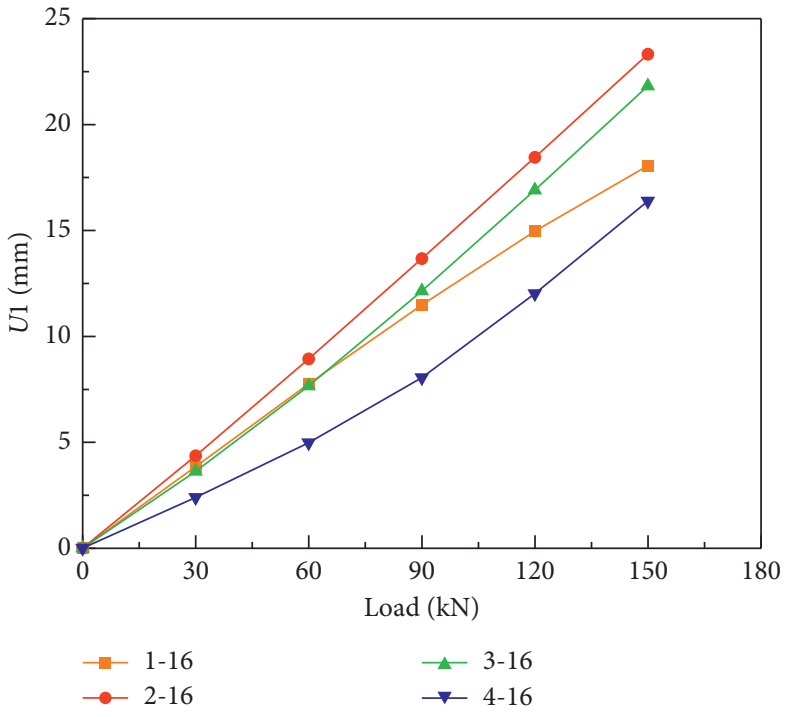

(d)

Figure 10: U1: (a) P1; (b) P3; (c) P5; (d) P6.

peak point close to pile top was large. The lower the pile section position was, the smaller the change of earth pressure was. The length of pile affected by load was shorter than the design length.

2.3.4. Stability Analysis of Slope. Based on the strength reduction method, the cohesion and internal friction angle of the soil were reduced. According to the relationship curve of the reduction coefficient FV and the $\mathrm{U} 1$ of the soil at the slope foot, the stability of the slope was determined. When the slope was unstable, the sliding body was in the state of infinite plastic flow, appearing large displacement and plastic deformation. According to the feature, in the process of finite element calculation, the abrupt change of plastic strain or displacement of the node on the sliding surface can be regarded as a sign of the overall instability of the slope [14].
When the displacement increased and the reduction coefficient was basically unchanged, the slope was unstable. The value, corresponding to the reduction coefficient variation was always less than 0.001 , was seen as the overall safety factor of the slope. As shown in Figure 14, among the four models, the safety factor was $2.42,2.66,2.78$, and 2.84, respectively. The factor increased slowly with the increase in rise-span ratio that can satisfy the requirement for actual engineering and verify the feasibility of spatial arc antislide pile.

\section{Indoor Model Test}

\subsection{Test Scheme}

3.1.1. Materials. The soil used in the test was loess. The slope model was tamped layer by layer, and the compaction 


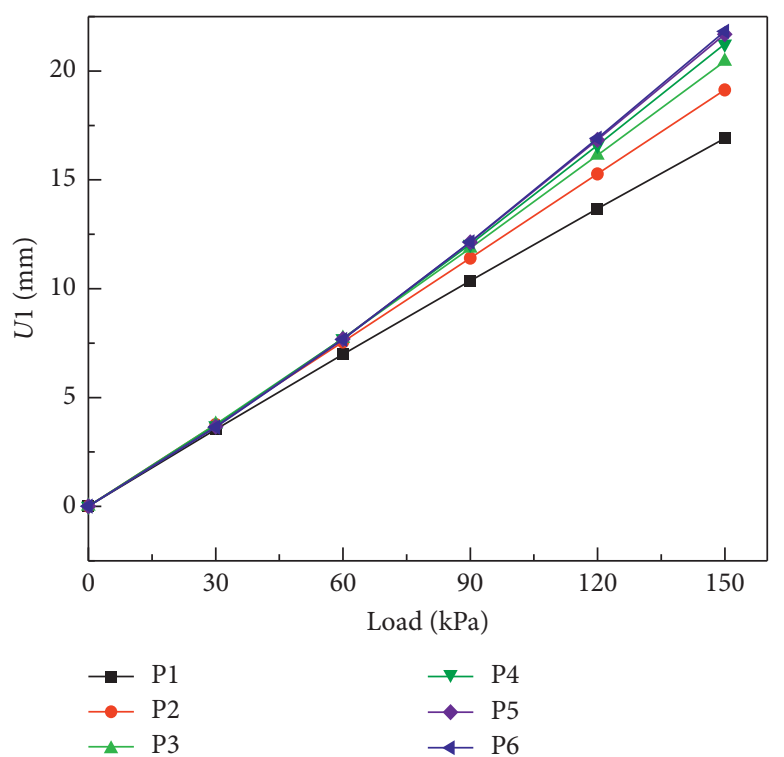

(a)

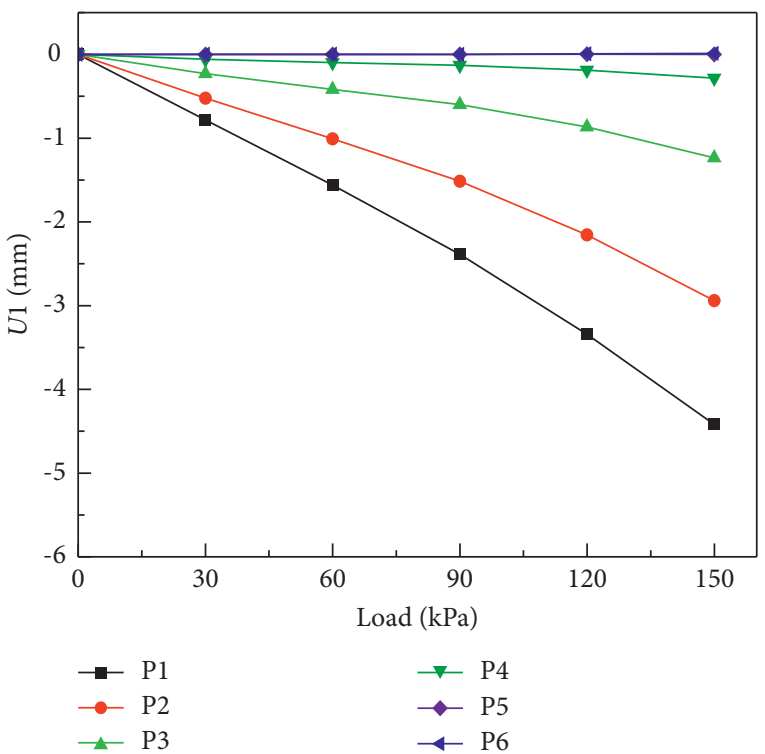

(b)

FIGURE 11: Displacement at the pile top (3-16): (a) U1; (b) U2.
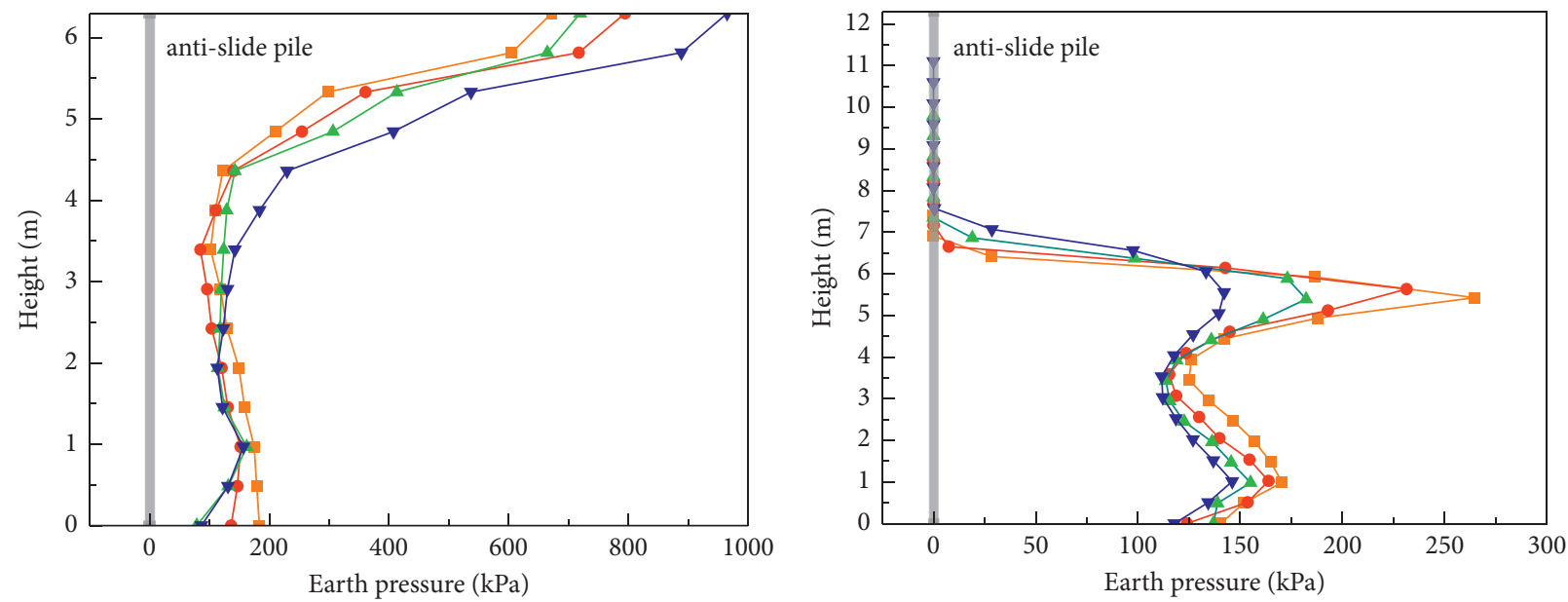

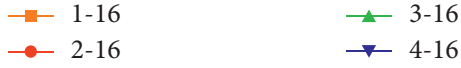

(a)

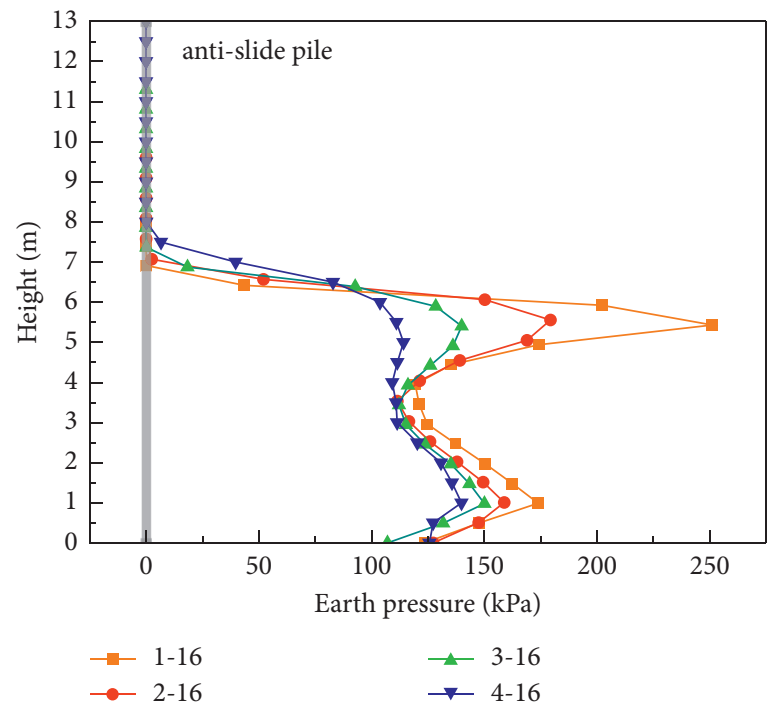

(c)

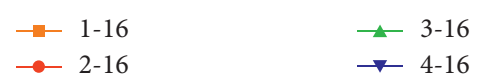

(b)
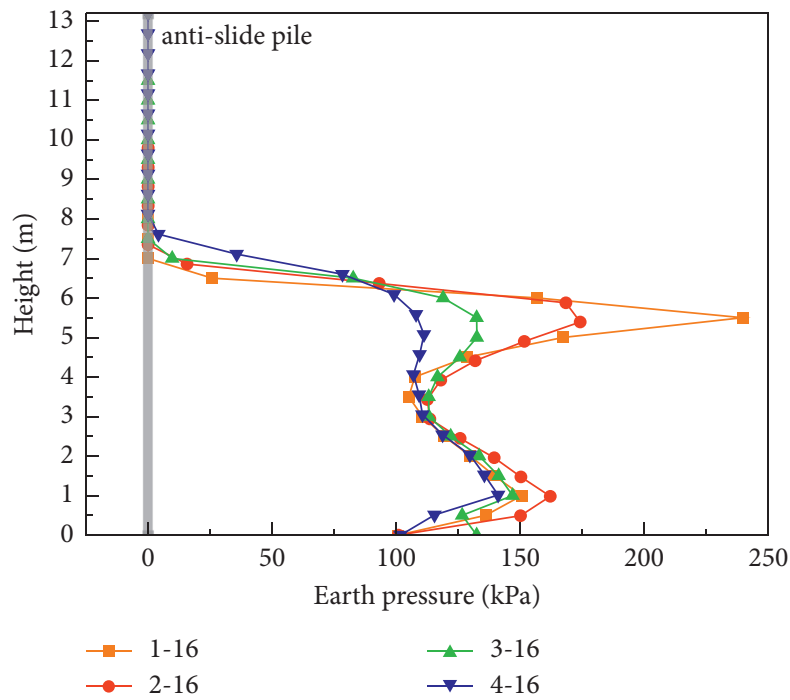

(d)

FIgURE 12: Earth pressure in front of pile: (a) P1; (b) P3; (c) P5; (d) P6. 

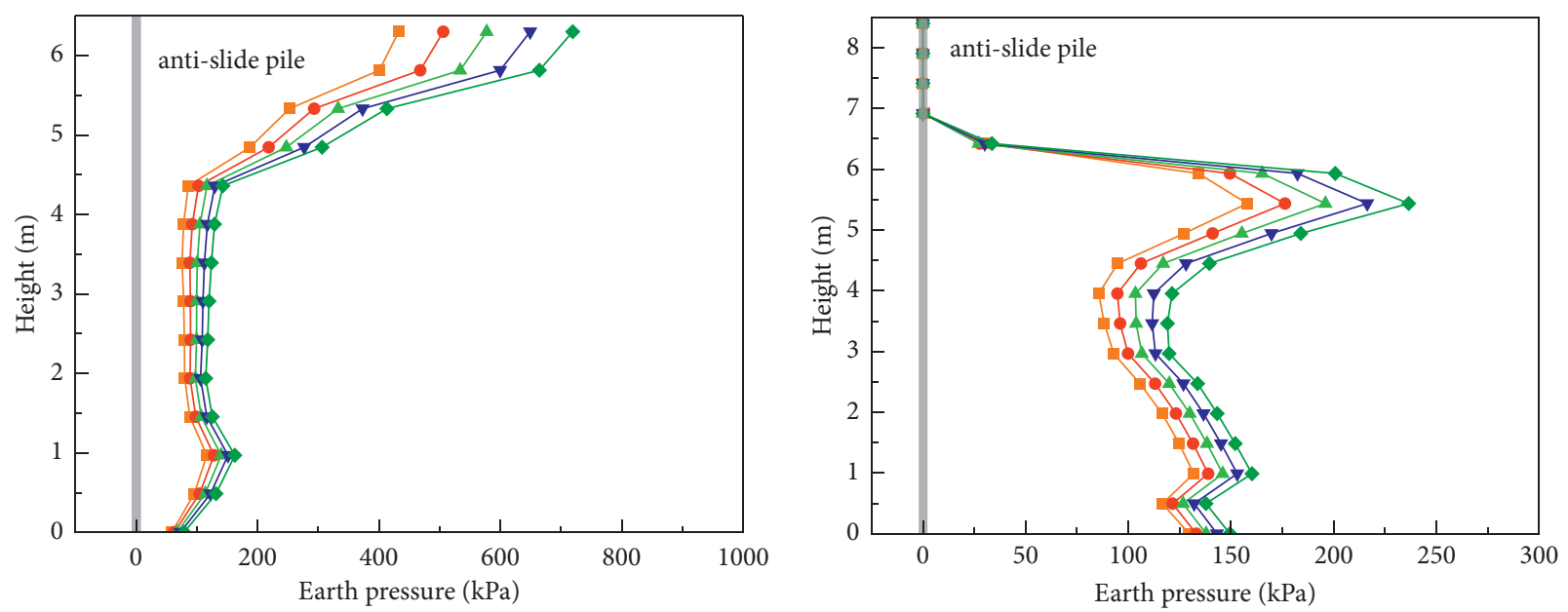

$-30 \mathrm{kPa}$
$-60 \mathrm{kPa}$
$-\quad 90 \mathrm{kPa}$

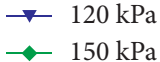

$\longrightarrow \quad 30 \mathrm{kPa}$
$-60 \mathrm{kPa}$
$-\quad 90 \mathrm{kPa}$

$\rightarrow 120 \mathrm{kPa}$

(a)

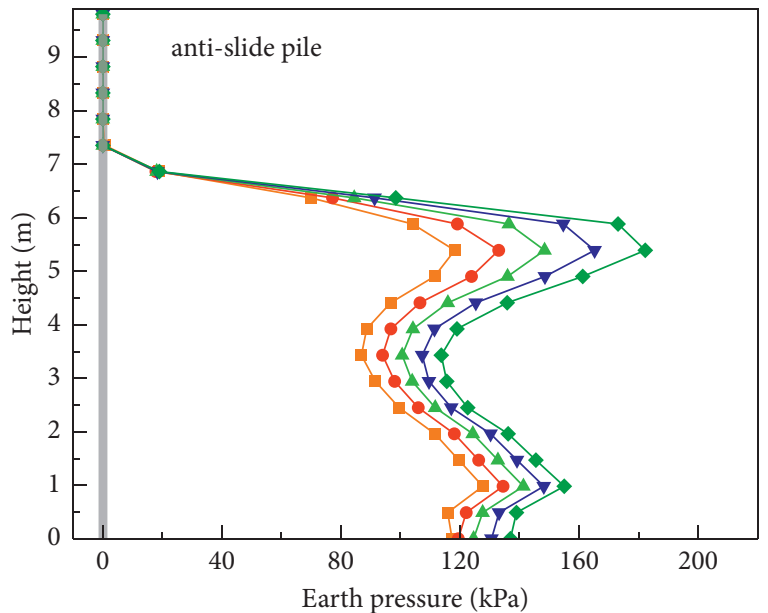

(b)
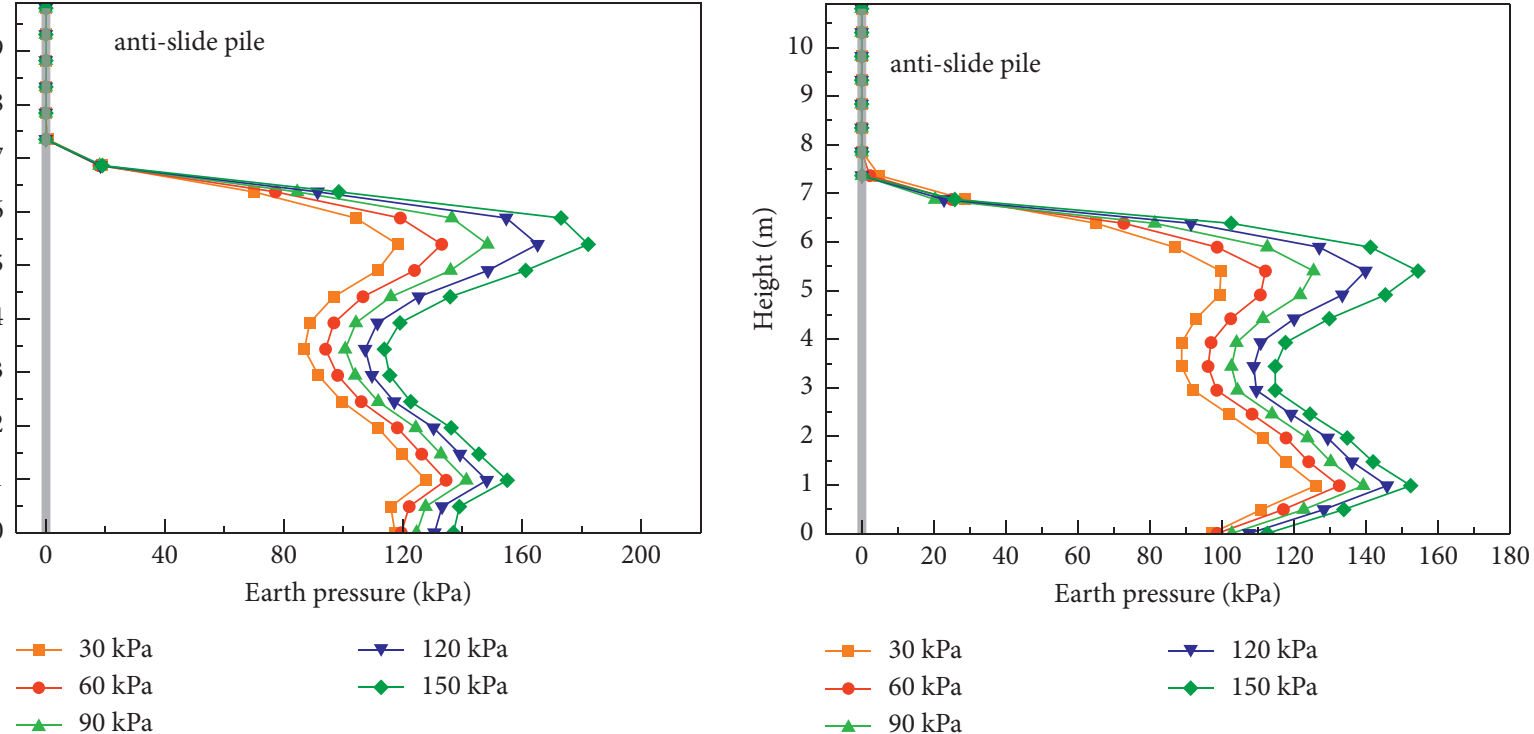

$\rightarrow-120 \mathrm{kPa}$

$-\quad 30 \mathrm{kPa}$

$60 \mathrm{kPa}$

$\rightarrow-120 \mathrm{kPa}$

- $90 \mathrm{kPa}$

(c)

(d)

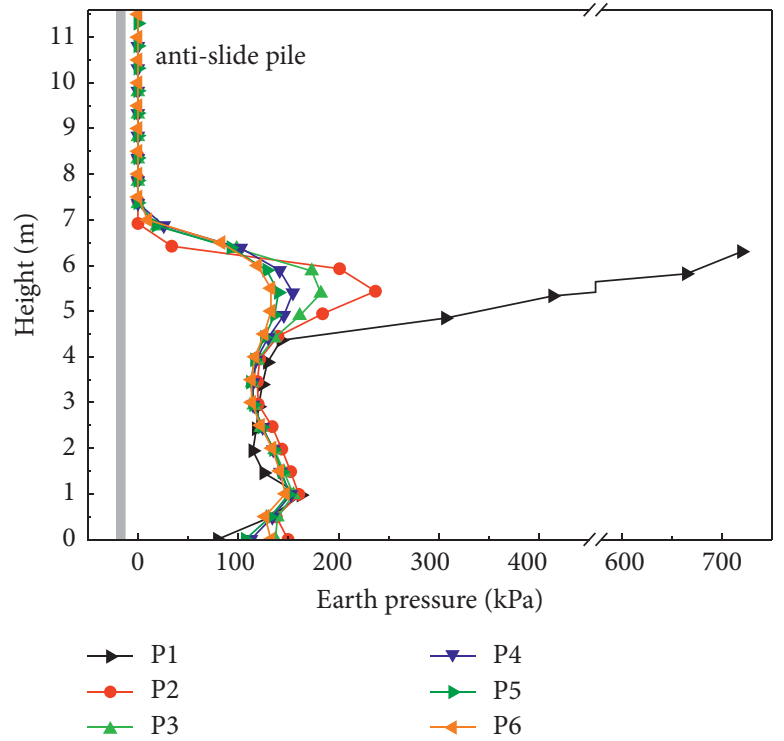

(e)

Figure 13: Earth pressure in front of pile (3-16): (a) P1; (b) P3; (c) P5; (d) P6; (e) $150 \mathrm{kPa}$ 


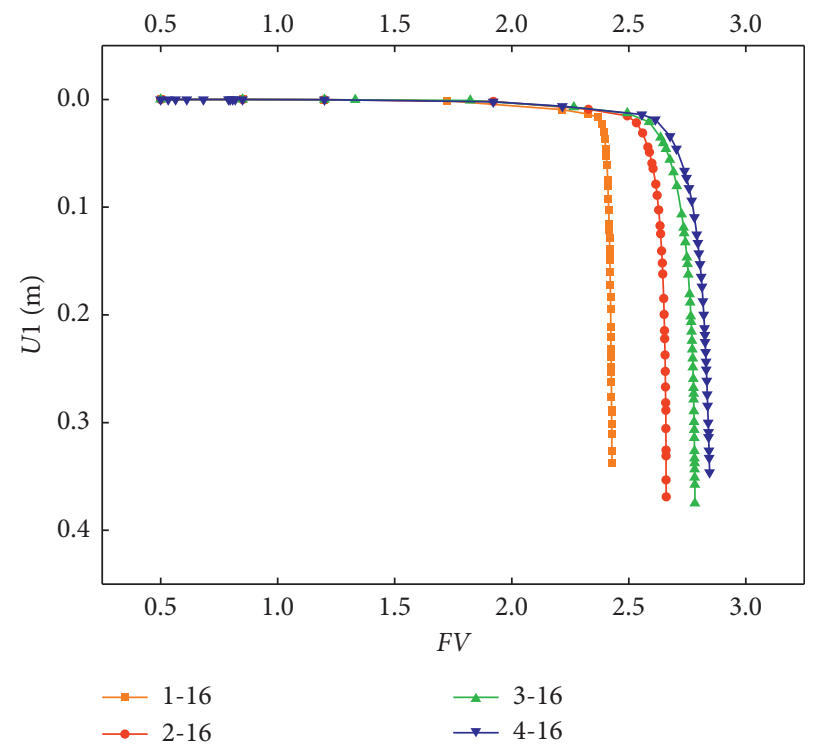

Figure 14: FV-U1 curves.

TABLE 3: Parameters of soil.

\begin{tabular}{lcccc}
\hline Name & Unite weight $\left(\mathrm{kN} / \mathrm{m}^{3}\right)$ & Internal friction angle $\left(^{\circ}\right)$ & Cohesion $(\mathrm{kPa})$ & Water content $(\%)$ \\
\hline Loess & 20.8 & 30.05 & 42.5 & 18 \\
\hline
\end{tabular}

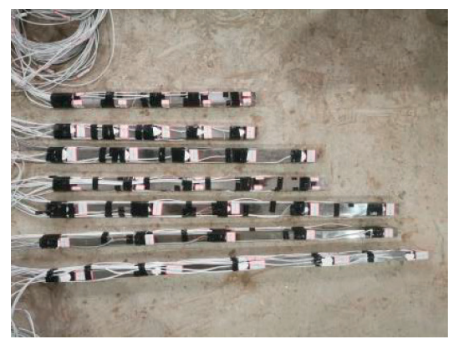

(a)

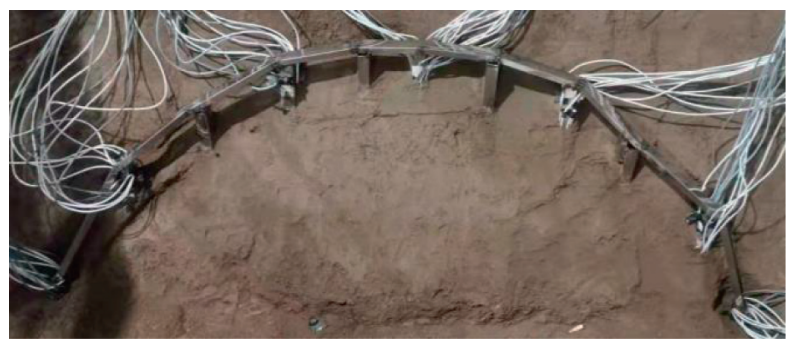

(b)

FIGURE 15: Supporting structure: (a) antislide piles and (b) coupling beam.

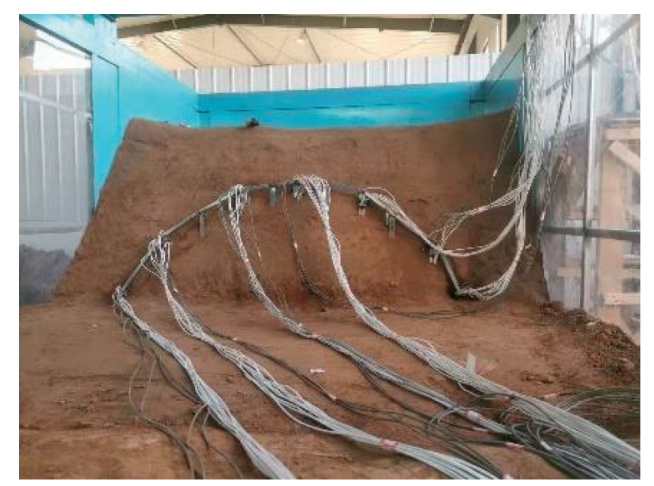

FIGURE 16: Slope model. 


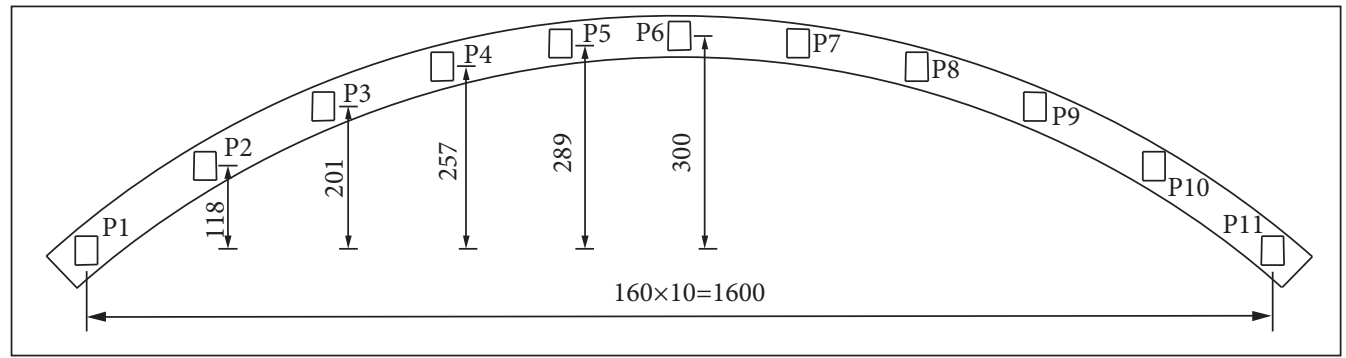

FIGURE 17: Layout of antislide piles (mm).

Table 4: Pile length $(\mathrm{cm})$.

\begin{tabular}{lcccccc}
\hline Number & P1(11) & P2(10) & P3(9) & P4(8) & P5(7) & P6 \\
\hline Length & 63 & 84 & 98 & 108 & 113 & 115 \\
\hline
\end{tabular}

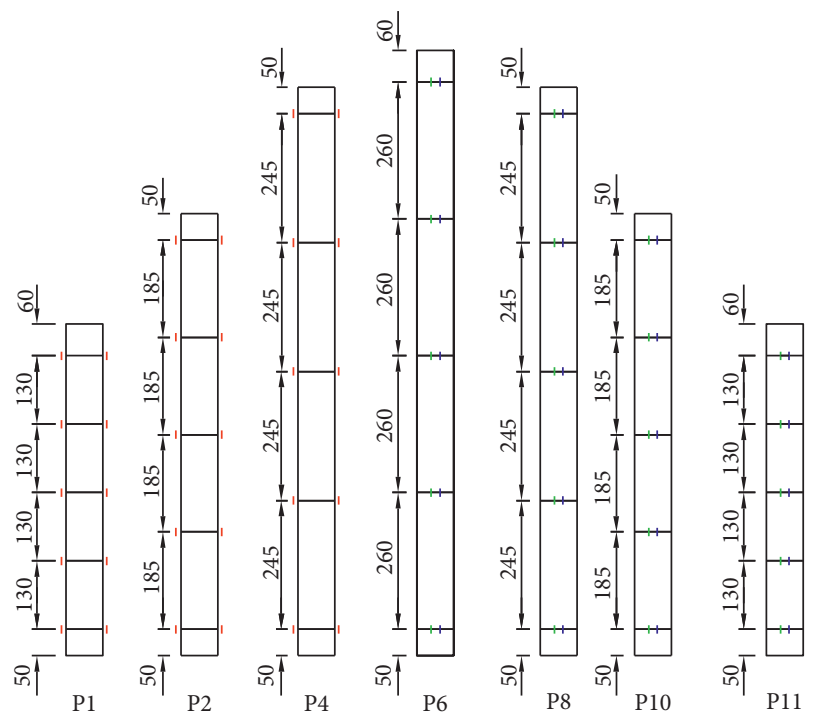

1 :Strain at the left and right of pile

I :Strain at the back of pile

I :Strain at the front of pile

Figure 18: Layout of strain gauge (mm).

coefficient met the design requirements, not less than 0.9. The basic parameters of the soil are shown in Table 3.

The material of antislide pile and coupling beam was stainless steel, the size of the cross section was $40 \mathrm{~mm} \times 30 \mathrm{~mm}$ and $30 \times 15 \mathrm{~mm}$, respectively, and the elastic modulus was $190 \mathrm{GPa}$, as shown in Figure 15.

3.1.2. Slope Model. Considering the operability, the validity of the test results, and the size of the slope, the slope model with the similarity ratio of $1: 10$ was used as the test object. According to the geometric similarity ratio $\left(C_{L}=10\right)$, the other physical quantities were determined.

The plane dimension of the experimental box is $6 \mathrm{~m} \times 2.2 \mathrm{~m}$, and the bottom of the box was natural saturated soil. Tthe length of the slope was $2.2 \mathrm{~m}$, the width was $1 \mathrm{~m}$, and the angle of the slope $60^{\circ}$, as shown in Figure 16 .

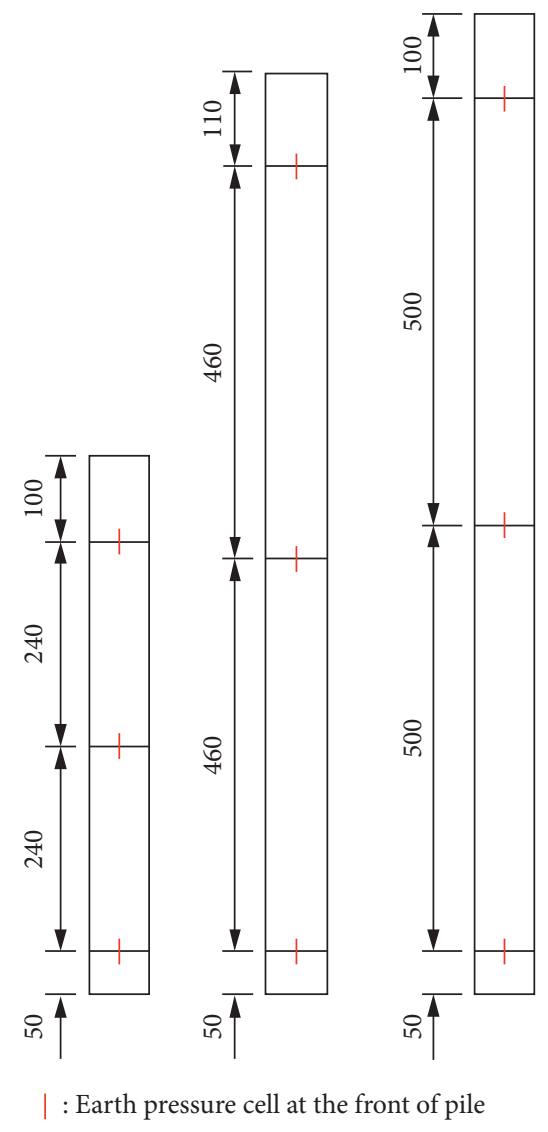

Figure 19: Layout of earth pressure cell (mm).

Figure 17 is the layout of antislide piles. Table 4 is the length of the piles. The coupling beam connected all pile top by welding to compose an integral supporting system.

\subsection{Measurement Scheme}

3.2.1. Strain. The strain of pile body was measured by strain gauge BF1K-3EB. The strain gauges were arranged on the right and left of the P1, P2, and P4 and the back and front of 


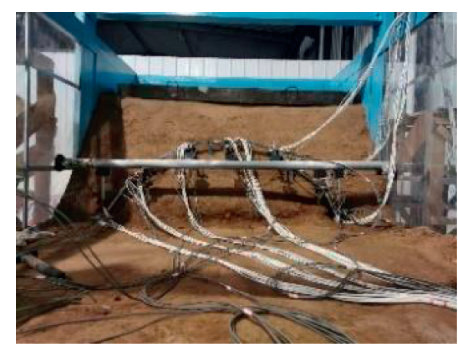

(a)

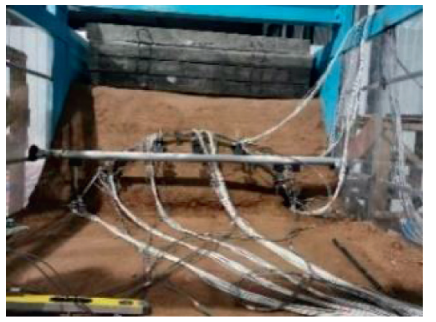

(d)

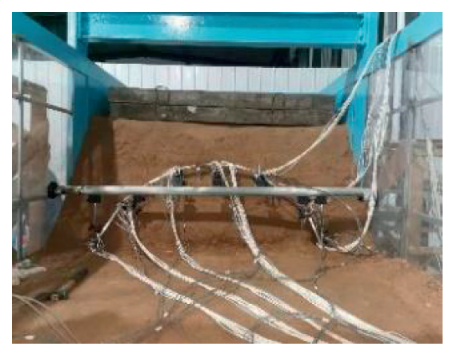

(b)

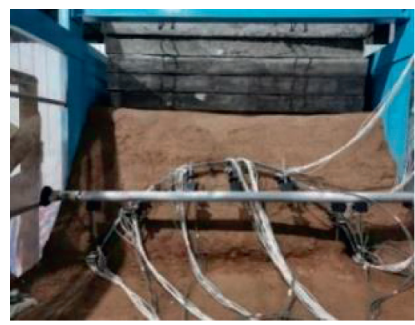

(e)

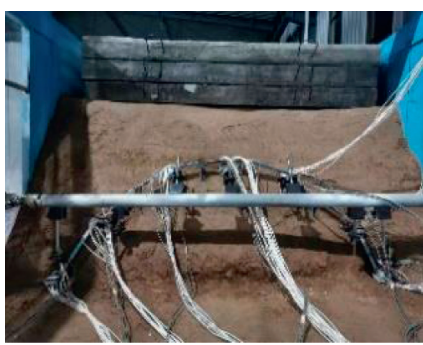

(c)

Figure 20: Process of loading: (a) Level 1; (b) Level 2; (c) Level 3; (d) Level 4; (e) Level 5.

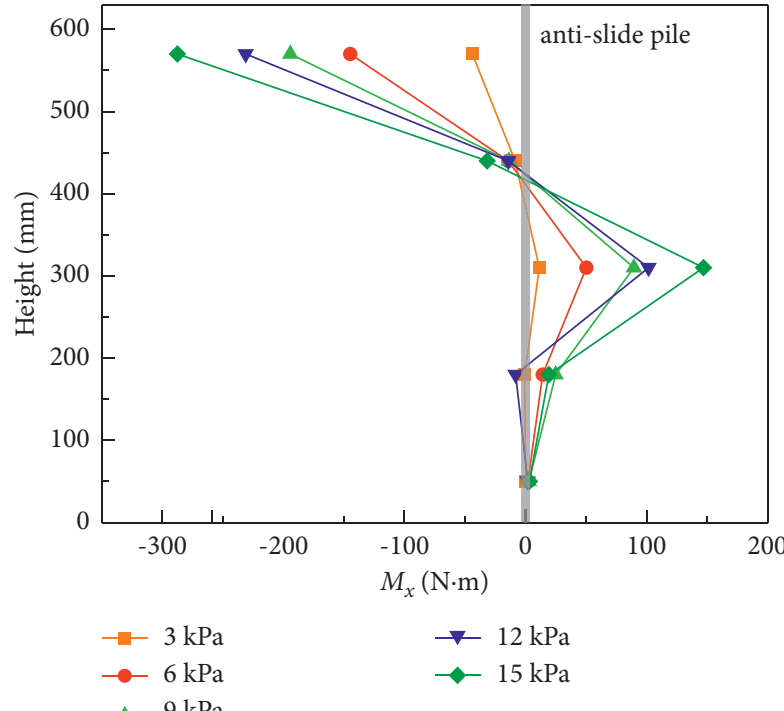

(a)

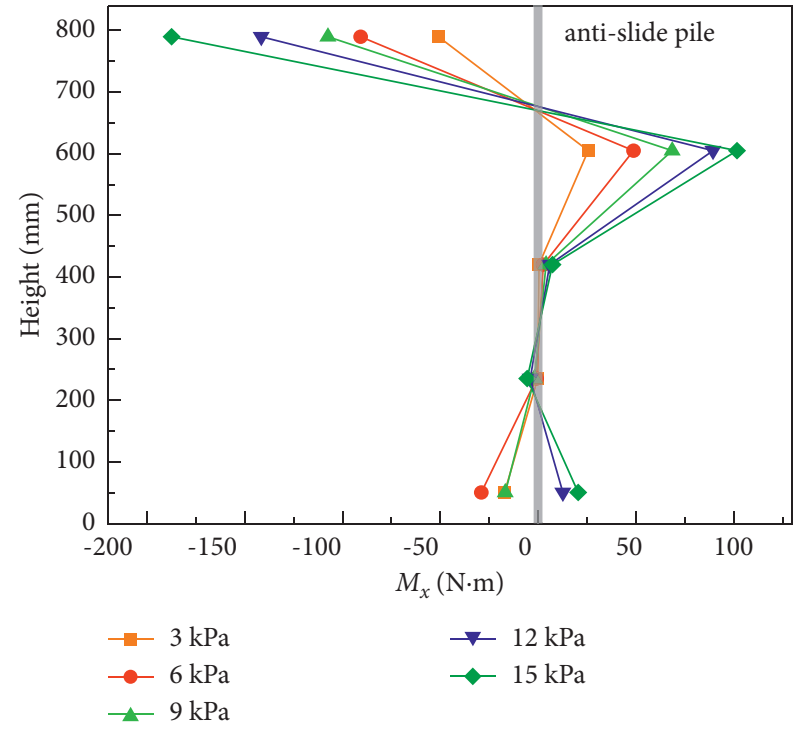

(b)

Figure 21: Continued. 


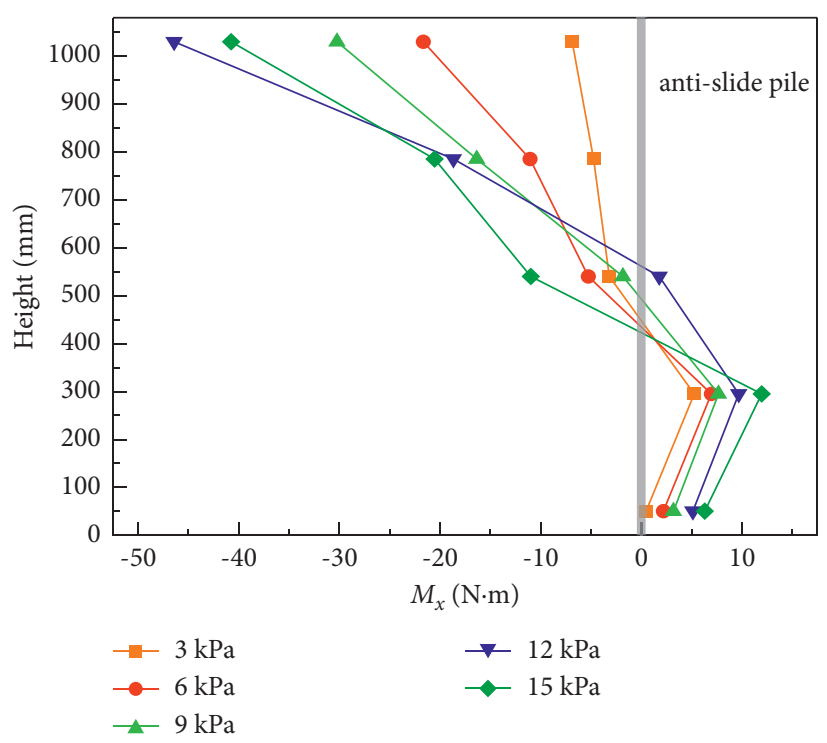

(c)

Figure 21: $M_{x}$ : (a) P1; (b) P2; (c) P4.
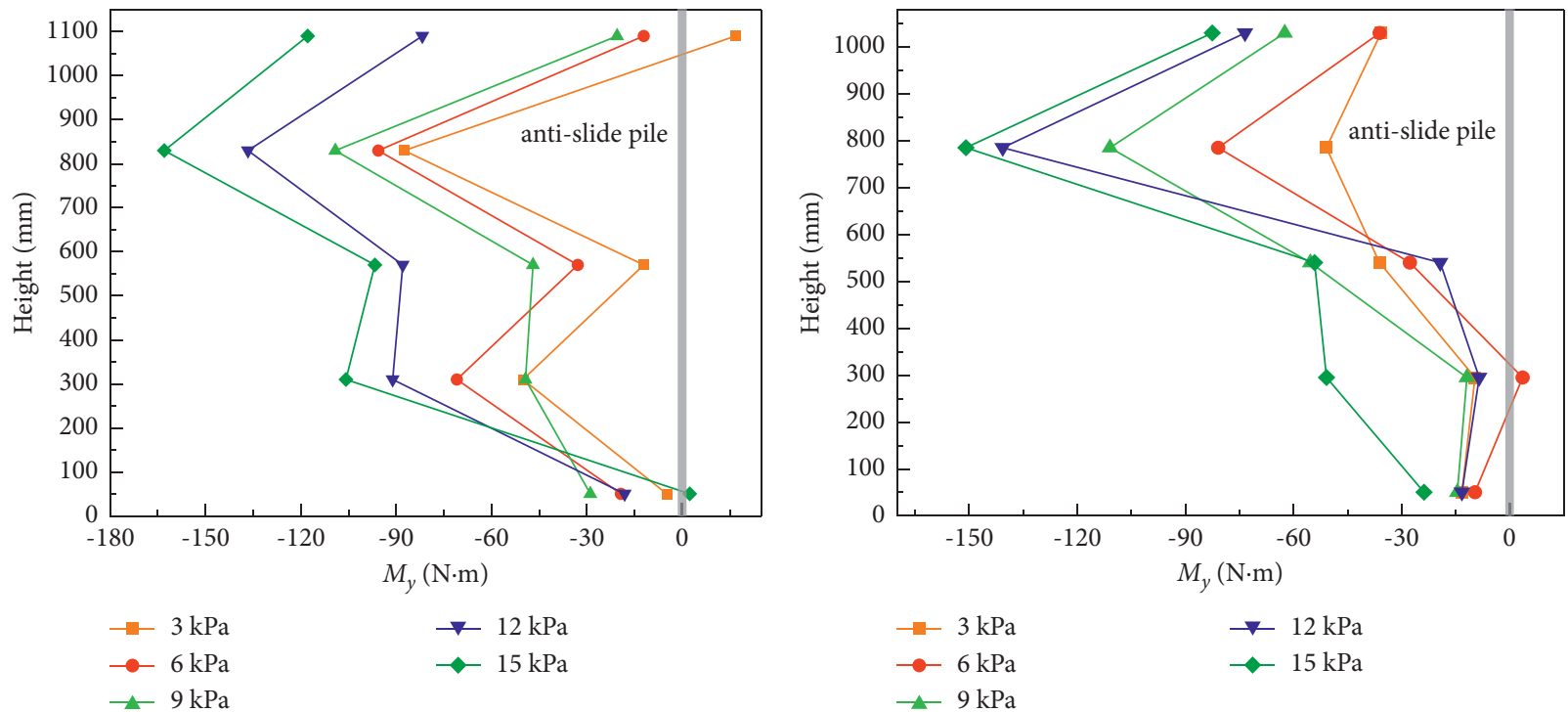

(a)

(b)

Figure 22: Continued. 


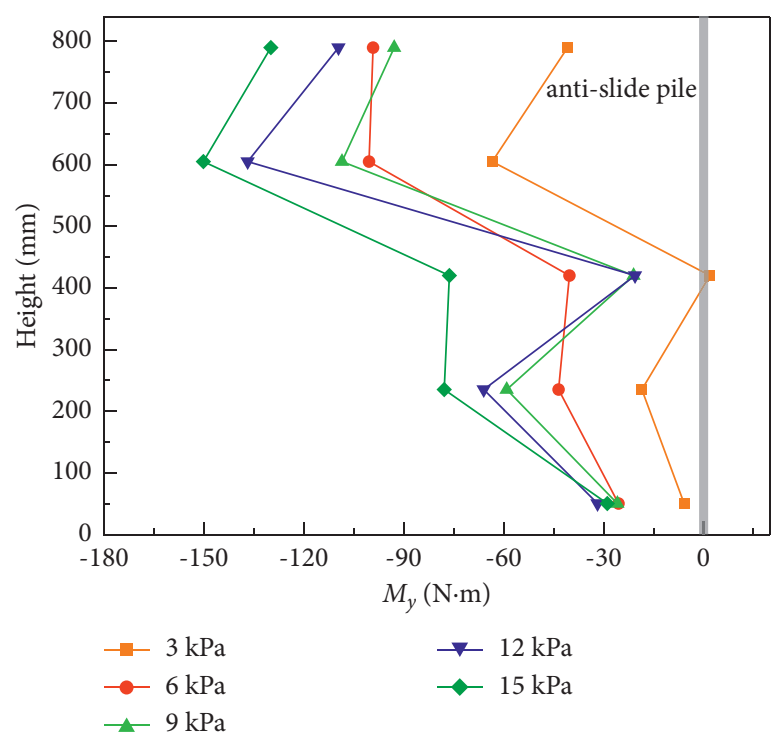

(c)

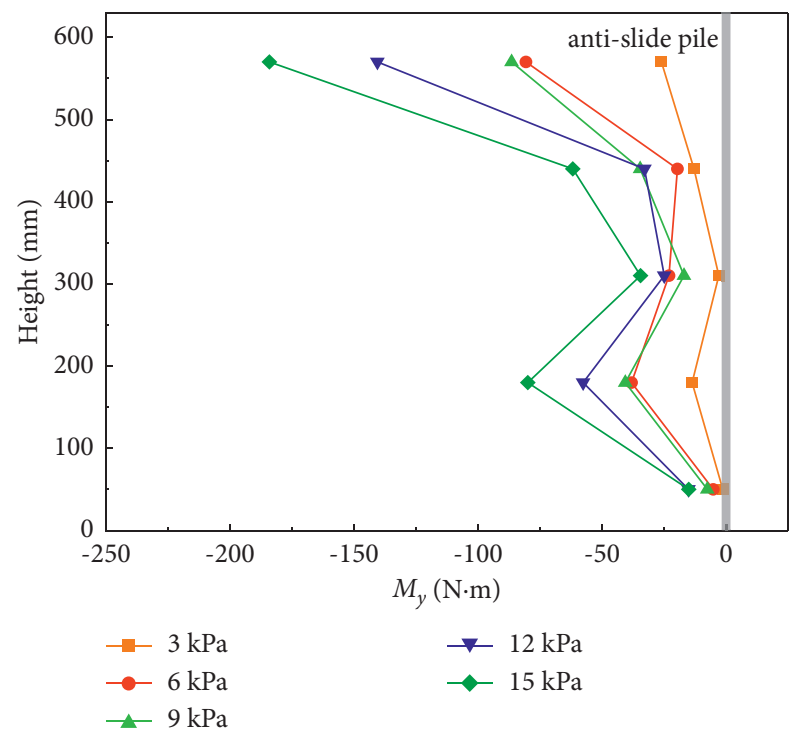

(d)

Figure 22: $M_{y}$ : (a) P6; (b) P8; (c) P10; (d) P11.

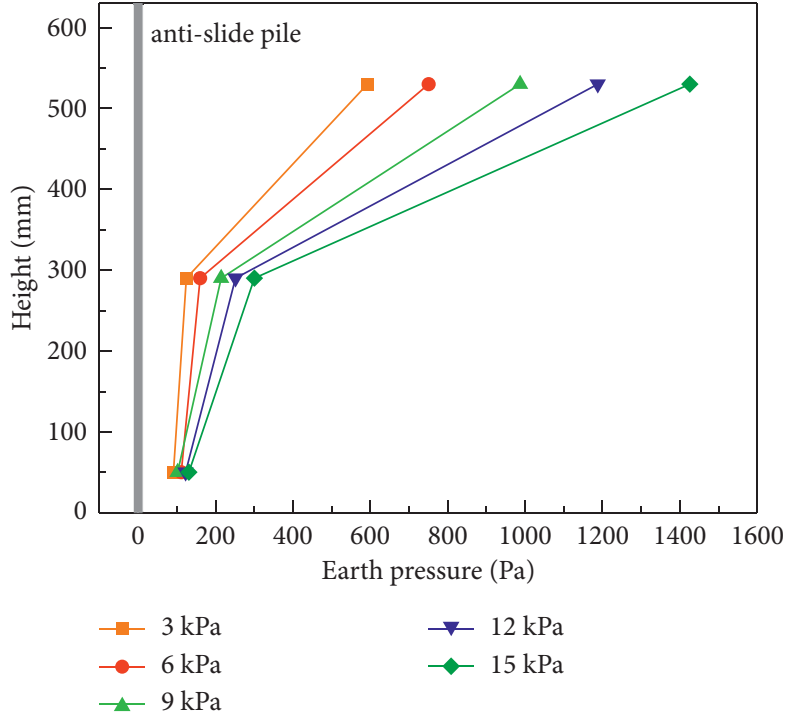

(a)

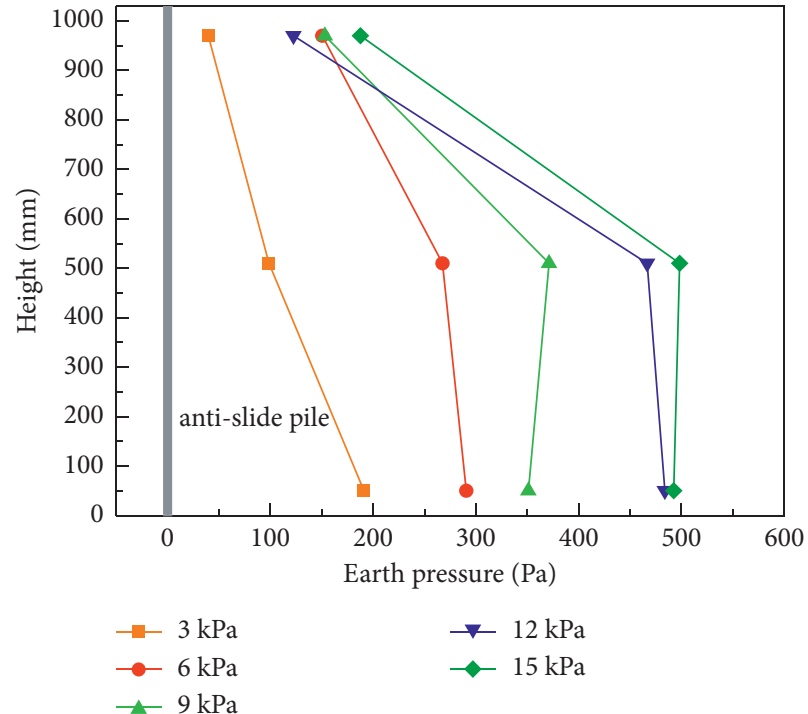

(b)

Figure 23: Continued. 


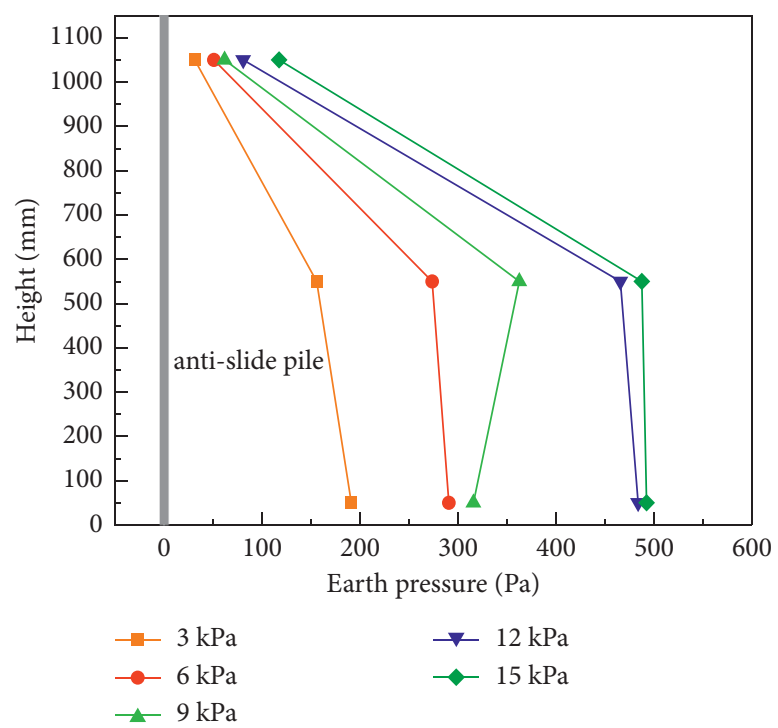

(c)

Figure 23: Earth pressure in front of pile: (a) P1; (b) P4; (c) P6.

P6, P8, P10, and P11, as shown in Figure 18. The data were recorded by the ST3826E static strain analysis system, the resolution is $1 \mu \varepsilon$, and the recording interval was 5 minutes.

3.2.2. Earth Pressure. The earth pressure was measured by YTDZ031 micro earth pressure cell. In the tamping process, the earth pressure cell was attached on the P1, P4, and P6, and the position of the cell was shown in Figure 19.

3.3. Loading Scheme. During the loading process, the concrete slab was used as load, and the size was $2 \mathrm{~m} \times 1 \mathrm{~m} \times 0.12 \mathrm{~m}$. Each slab is $3 \mathrm{kPa}(25 \mathrm{kN} /$ $\mathrm{m}^{3} \times 0.12 \mathrm{~m}=3 \mathrm{kPa}$ ), and there were 5 levels, as shown in Figure 20. When the variation of strain was few, the next load could be applied.

\subsection{Test Results and Discussion}

3.4.1. Bending Moment. According to the conversion equation between strain and bending moment, the recorded bending strain can be converted into bending moment of pile cross section. $M_{x}$ of $\mathrm{P} 1, \mathrm{P} 2$, and $\mathrm{P} 4$ is shown in Figure 21. The maximum of each pile appeared at the pile top. The bending moment of the pile bottom was close to zero, so the pile bottom can be seen as hinge joint. $M_{x}$ of P1 was the largest, and P4 was the smallest and P2 was between the two piles because the coupling beam transferred load to the pile at arch foot. The pile at arch foot was set as support of the supporting system.

The distribution of $M_{y}$ was different from $M_{x} . M_{y}$ was negative, and that of a few sections was positive, as shown in Figure 22. The maximum of $M_{y}$ of $\mathrm{P} 6, \mathrm{P} 8$, and $\mathrm{P} 10$ appeared at the section below the pile top, but the maximum of P1 appeared at the pile top. For the pile located on the middle position, the constraint of coupling beam was evident while the pile at the arch foot depended on flexural stiffness and soil resistance to resist sliding force and the load transferred from coupling beam.

3.4.2. Earth Pressure. The variation of earth pressure in front of P1, P4, and P6 is shown in Figure 23. The earth pressure in front of P1 increased from the bottom to the top. The soil resistance at the pile top reached the maximum. The earth pressure in front of the top of P4 and P6 was smaller, and the variation at the lower half part was a few. Among the three piles, the maximum soil resistance was at the top of P1, which resists much load. In actual slope engineering, the pile at the arch foot should be arranged on the stable soil at the both sides of landslide, fully utilizing soil resistance to bear sliding force.

\section{Conclusion}

Because of the limited number of measuring points in the experiment and there were many uncertain factors, the data of the indoor model test fluctuated, but the results of the experiment and numerical simulation were basically the same in the overall trend, which can be verified with each other. The detailed conclusions were as follows:

(1) The antislide pile can be simplified as a vertical beam that the one end was hinge joint and the other was rigid joint. The stress state of antislide pile was more reasonable. With the increase in rise-span ratio, the load transferred to the pile at the arch foot was larger, the bending moment of the pile and the displacement of the pile top and the earth pressure were also greater, and the effect of coupling beam transferring load was more evident. From arch roof to arch foot, $M_{x}$ and U2 increased continuously, which reflected the load transfer law of spatial arc antislide pile. 
(2) Within a certain depth near the pile top, the soil in front of pile was loose, the earth pressure was zero, and the position of the stable soil was deeper. In the numerical model with smaller rise-span ratio, the middle pile was closer to slope foot and the first earth pressure peak point away from pile top was larger. For the pile on the slope foot, the displacement of the pile top was smaller, and the earth pressure was greater. So, the stable soil at the arch foot provides better support and should be fully utilized in landslide treatment.

(3) The axial force of coupling beam was negative that can fully utilize the compressive performance of concrete and avoid bending-shear failure.

(4) Among the four numerical models, the safety factor was $2.42,2.66,2.78$, and 2.84 , respectively, which can satisfy the requirement for actual engineering. However, the variation amplitude of the safety factor was a few.

(5) In the model with the rise-span ratio of 3-16, there were lots of advantages, such as smaller displacement at the pile top, larger safety factor and bending moment compared with the model with smaller risespan ratio. Compared with the model with rise-span ratio of 4-16, in the recommended model, the total pile length was smaller and the soil in front of the pile was more stable, which can provide lots of soil resistance. In actual slope engineering, the layout of spatial arc antislide pile should adapt to the change of terrain altitude as far as possible, and the rise-span ratio should be set at about 3-16.

\section{Data Availability}

The data used to support the findings of this study are included within the article.

\section{Conflicts of Interest}

The authors declare that they have no conflicts of interest.

\section{Acknowledgments}

The research described in the paper was supported by National Natural Science Foundation of China (Nos. 51878554 and 41672308) and Key Projects of Shaanxi Natural Science Basic Research Program (No. 2018JZ5012).

\section{References}

[1] Y. Chen, Z. Zhang, and H. Liu, "Study of the seismic performance of hybrid A-frame micropile/MSE (mechanically stabilized earth) wall," Earthquake Engineering and Engineering Vibration, vol. 16, no. 2, pp. 275-295, 2017.

[2] X. L. Yang and S. Zhang, "Stability analysis of 3D cracked slope reinforced with piles," Computers and Geotechnics, vol. 122, Article ID 103544, 2020.

[3] Y. He, H. Hazarika, N. Yasufuku, Z. Han, and Y. Li, "Threedimensional limit analysis of seismic displacement of slope reinforced with piles," Soil Dynamics and Earthquake Engineering, vol. 77, pp. 446-452, 2015.

[4] H. Tang, X. Hu, C. Xu, C. Li, R. Yong, and L. Wang, "A novel approach for determining landslide pushing force based on landslide-pile interactions," Engineering Geology, vol. 182, pp. 15-24, 2014.

[5] S. F. Zhang, G. J. Zhang, X. Y. Zhang, L. C. Chen, and S. Zheng, "Influences on antislide piles used for slope reinforcement: numerical simulation based on the soil arching effect," Mathematical Problems in Engineering, vol. 2020, Article ID 7651080, 15 pages, 2020.

[6] J. P. Xin, X. S. Tang, Y. R. Zheng, and D. Zhang, "Large-scale model tests of single-row anti-slide micropiles," Rock and Soil Mechanics, vol. 36, no. 4, pp. 1050-1056, 2015.

[7] T. H. Qian and H. M. Tang, "Spatial calculation model for portal double row anti-slide piles," Rock and Soil Mechanics, vol. 30, no. 4, pp. 1137-1141, 2009.

[8] Y. Wang, J. Feng, X. D. Xie, B. Lai, and T. Yang, "In-situ experimental study of anti-sliding mechanism of micro-pile combined structure," Rock and Soil Mechanics, vol. 39, no. 11, pp. 4226-4231, 2018.

[9] P. Rao, L. Zhao, Q. Chen, and S. Nimbalkar, "Three-dimensional limit analysis of slopes reinforced with piles in soils exhibiting heterogeneity and anisotropy in cohesion," Soil Dynamics and Earthquake Engineering, vol. 121, pp. 194-199, 2019.

[10] X. Guo, Z. Wang, P. Geng, C. Chen, and J. Zhang, "Ground surface settlement response to subway station construction activities using pile-beam-arch method," Tunnelling and Underground Space Technology, vol. 108, Article ID 103729, 2021.

[11] Y. X. Yu, The reasearch about the structure of the arc-shaped element combination anti-slide pile, Ph.D. thesis, Wuhan University of Technology, Wuhan, China, 2006.

[12] H. Wang, Experimental study on the performance of the arch anti-slide pile-wall supporting structure system, Ph.D. thesis, Chang'an University, Xi'an, China, 2011.

[13] Z. W. Zhang and R. G. Deng, "Theoretical study of spatial anti-slide structure of arc interval row piles with coupling beam on pile top," Rock and Soil Mechanics, vol. 34, no. 12, pp. 3403-3409, 2013.

[14] Y. R. Zheng, S. Y. Zhao, W. X. Kong, and C. J. Deng, "Geotechnical engineering limit analysis using finite element method," Rock and Soil Mechanics, vol. 26, no. 1, pp. 163-168, 2005. 